\title{
Hierarchical organization of a Sardinian sand dune plant community
}

Valentina Cusseddu, Giulia Ceccherelli, Mark Bertness

Coastal sand dunes have attracted the attention of plant ecologists for over a century, but they have largely relied on correlations to explain dune plant community organization. We examined long-standing hypotheses experimentally that sand binding, inter-specific interactions, abiotic factors and seedling recruitment are drivers of sand dune plant community structure in Sardinia, Italy. Removing foundation species from the fore-, middle- and back-dune habitats over 3 years led to erosion and habitat loss on the foredune and limited plant recovery that increased with dune elevation. Reciprocal species removals in all zones suggested that inter-specific competition is common, but that dominance is transient, particularly due to sand burial disturbance in the middle-dune. A fully factorial 2-year manipulation of water, nutrient availability and substrate stability revealed no significant proximate response to these physical factors in any dune zone. In the fore- and middle-dune, plant seeds are trapped under adult plants during seed germination, and seedling survivorship and growth generally increase with dune height in spite of increased herbivory in the back-dune. Sand and seed erosion leads to limited seed recruitment on the fore-dune while high summer temperatures and preemption of space lead to competitive dominance of woody plants in the back-dune. Our results suggest that Sardinian sand dune plant communities are organized hierarchically, structured by sand binding foundation species on the fore-dune, sand burial in the middle-dune and increasingly successful seedling recruitment, growth and competitive dominance in the back-dune. 
1

2

Hierarchical organization of a Sardinian sand dune plant community

3

4

5

6

7

8

9

10

11

12

${ }^{1}$ Department of Science for Nature and Environmental Resources, University of Sassari, Italy;

${ }^{2}$ Department of Ecology and Evolutionary Biology, Brown University

13 Corresponding Author:

14 Valentina Cusseddu ${ }^{1}$

15 Via Piandanna 4, 07100, Sassari, Italy

16

e-mail address: vcusseddu@uniss.it 
18 Abstract (246 words). Coastal sand dunes have attracted the attention of plant ecologists for over

19 a century, but they have largely relied on correlations to explain dune plant community

20

21

22

23

24 organization. We examined long-standing hypotheses experimentally that sand binding, interspecific interactions, abiotic factors and seedling recruitment are drivers of sand dune plant community structure in Sardinia, Italy. Removing foundation species from the fore-, middle- and back-dune habitats over 3 years led to erosion and habitat loss on the fore-dune and limited plant recovery that increased with dune elevation. Reciprocal species removals in all zones suggested that inter-specific competition is common, but that dominance is transient, particularly due to sand burial disturbance in the middle-dune. A fully factorial 2-year manipulation of water, nutrient availability and substrate stability revealed no significant proximate response to these physical factors in any dune zone. In the fore- and middle-dune, plant seeds are trapped under adult plants during seed germination, and seedling survivorship and growth generally increase with dune height in spite of increased herbivory in the back-dune. Sand and seed erosion leads to limited seed recruitment on the fore-dune while high summer temperatures and preemption of space lead to competitive dominance of woody plants in the back-dune. Our results suggest that Sardinian sand dune plant communities are organized hierarchically, structured by sand binding foundation species on the fore-dune, sand burial in the middle-dune and increasingly successful seedling recruitment, growth and competitive dominance in the back-dune. 
41 Understanding the mechanisms biotic and abiotic that generate spatial patterns in natural

42 communities is a major goal of ecology and is critical for developing ecology into a predictive

43 science that can inform ecosystem management and contribute to conservation (Morin 2011).

44 Many natural communities are structured and defined by foundation species, sensu Dayton

45 (1975). Foundation species are defined operationally as common, abundant species that build and

46 maintain habitats, ameliorating potentially limiting physical and biological factors, thus

47 providing habitat for other species (Jones et al. 1994, Bruno and Bertness 2001, Ellison et al.

48 2005, Angelini et al. 2011). Examples of foundation species-dependent ecosystems include

49 forests, coral reefs, salt marshes, mangroves, mussel and oyster reefs, which are all built and

maintained by numerically-dominant habitat forming foundation species (Bruno and Bertness

51 2001). Amelioration of potentially limiting physical and/or biotic conditions is a hallmark of

52 foundation species-based ecosystems. Coastal sand dunes are physically-harsh habitats for the

53 xerophytic plants that dominate them and are best understood as foundation species-based

54 ecosystems (Olff et al. 1993).

55 Recently, it has been suggested that foundation species-based ecosystems are commonly

56 hierarchical, where the amelioration of potentially limiting stresses is responsible for ecosystem

57 establishment and maintenance, but that other species interactions are often responsible for generating the most conspicuous, but superficial spatial patterns in these communities (Bruno

59 and Bertness 2001, Bruno et al. 2003, Altieri et al. 2007, Angelini et al. 2011). While this model

60 of community organization appears to be widespread (Bruno and Bertness 2001), most evidence

61 for hierarchical organization is anecdotal or correlative with few explicit experimental tests (for

62 exceptions see Altieri et al. 2007, Angelini and Silliman 2014). This is the case in spite of the 
63 potential importance of hierarchical community organization to conservation and management 64 strategies. Plant communities that occur at the land/sea interface, like sand dune, salt marsh, sea 65 grass and mangrove communities, provide important ecological functions including stabilizing 66 shorelines from erosion and storm damage, harboring animal diversity, providing nursery 67 habitats to threatened avifauna, marine turtles, and shellfish, as well as processing nutrient-rich

68 terrestrial runoff (Barbier et al. 2013). Preserving these services belongs to informed management facing increasing threats. Sand dunes, however, are generally not conservation priorities and not managed to protect their socio-economic benefits (Ehrenfeld 1990, Everard et al. 2010). Historically most research on sand dune communities has been descriptive and reliant on dated correlative literature (e.g. Cowles 1899, Oosting and Billings 1942, Mack and Harper 1977). Experimental work has been restricted to small-scale sand burial, seed dispersal and disturbance studies (Maun and Perumal 1999, Franks and Peterson 2003, Miller et al. 2010). Similarly, field studies of annuals and nurse plant effects, comparisons among chronosequences in plant species interactions (Lichter 2000, Franks 2003, Cushman et al. 2010), experimental grazer studies (Huntzinger et al. 2008) and plant/mycorrhizal associations studies (Gemma et al. 1989) have not examined large-scale patterns. Experimental studies of the roles of the dominant foundation species that have long been hypothesized to build and maintain sand dune plant communities by binding sand and ameliorating potentially limiting physical conditions such as water and nutrient

82 limitation are notably absent. Consequently, the critical interactions between biological and

83 physical processes that have been assumed to generate the organization of sand dune 84 communities have not been rigorously tested. 
85 Descriptive and correlative studies of sand dune communities suggest that substrate stabilization, 86 water and nutrient limitation, and plant facilitation and competition are the main drivers of sand

87 dune community structure and organization (Barbour et al. 1985, Ehrenfeld 1990, Lichter 1998, 88 Isermann 2011). Distinct plant zonation occurs in coastal sand dune systems (Hesp 1991, Lortie and Cushman 2007, Acosta 2009). On the seaward border of sand dunes, the fore-dune, a limited number of clonal pioneer plant species with deep roots trap and bind sand, initiating dune formation. These plants stabilize substrate, trap seeds, and grow vertically and horizontally as sand accumulates, building the seaward border of sand dunes (Cowles 1899, Oosting and Billings 1942). At higher elevations in the middle-dune, plant species diversity increases, but unvegetated free space remains common. At these elevations, substrate stabilization remains important, but inter-specific plant interactions, including facilitation (Franks 2003, Castanho et al. 2015) and competition (Lichter 2000), and water and nutrient limitation also appear to mediate plant success. In the back-dune, furthest from ocean winds and salt spray, the dominant physical stresses of substrate instability and low soil nutrients and moisture are less severe, plant cover typically reaches $100 \%$, and numerically-dominant woody shrubs or trees, appear to competitively displace plants that dominate lower dune elevations (Lichter 2000). This descriptive structure of dune communities is consistent with a hierarchical community organization model and the stress gradient hypothesis of community assembly.

The hierarchical model of community organization (Bruno and Bertness 2001, Ellison et al. 2005, Altieri et al. 2007) hypothesizes that within communities built by foundation species, dependent species are only able to persist through positive interactions and feedbacks initiated by the primary foundation species. The stress gradient hypothesis (Bertness and Callaway 1994, Maestre et al. 2009, He and Bertness 2014) proposes that the biological processes controlling 
108 community development shift from positive, facilitative interactions in physically and

109 biologically harsh environments to negative, competitive interactions in benign environments.

110 Many shoreline communities built and maintained by foundation species, such as salt marshes,

111 coral reefs, mangrove forests, mussel reefs, and seagrass beds, have been hypothesized to be

112 organized hierarchically by the general principles of the stress gradient hypothesis (Bruno and

113 Bertness 2001).

114 In this paper we examine long-standing assumptions of sand dune plant community ecology. We

115 hypothesize that sand dunes are organized hierarchically, initially built by facilitation, but

116 ultimately structured by spatially- and temporally predictable shifts from facilitative interactions

117 to competitive interactions and seedling recruitment across decreasing stress gradients. Many of

118 these patterns were initially theorized in classic descriptive work (Cowles 1899), but have never

119 been tested experimentally. We take a field experimental approach to test these underlying

120 assumptions and elucidate the sand dune community assembly by examining three hypotheses

121 that (1) foundation species are responsible for stabilizing the seaward border of the dune from

122 erosion and habitat loss (2) at intermediate dune elevations, inter-specific plant interactions, plant

123 resource availability, and seedling recruitment dictate plant abundance and distribution and (3) at

124 high dune elevations, reduced physical stresses lead to increased plant abundance, inter-specific

125 competitive dominance and displacement (Table 1).

\section{Materials ANd Methods}

127 Our study was carried out on the Badesi dunes (40 $56^{\prime} 45.571^{\prime}, \mathrm{N}, 8^{\circ} 49^{\prime} 41.048^{\prime}$ ' E) on the

128 North coast of Sardinia, in the Mediterranean Sea. It is a wide dune system at the mouth of

129 Coghinas River and has a plant community similar to other dune systems in Sardinia (Cusseddu

130 personal observations), it is within a Site of Community Importance (SIC) and the Town of 
131 Badesi gave us the field permit to undertake the field experiments (approval number: 3343 -

132 23/03/2012). The Coghinas dunes are almost $3 \mathrm{~km}$ long overlooking the Asinara Gulf, with a

133 width of approximately $500 \mathrm{~m}$. Sardinia has a warm temperate Mediterranean climate with hot,

134 dry summers and cooler, wet winters (Fadda 2016). As in other Mediterranean habitats, most

135 plant growth and reproduction occurs during the winter months (Blondel and Aronson 1999).

136 Previous studies of Sardinian sand dune plant communities reveal that they have high species

137 richness, endemism (Bacchetta et al. 2008, Prisco et al. 2012) and species adapted to physical

138 stress (Fenu et al. 2013).

140 To quantify the plant distribution across the Badesi dune, we surveyed transects at defined 141 distance from the coast-line. According to our findings, we defined three major dune plant zones:

142 the fore-dune, located on the seaward border of the dune and characterized by a steep lower

143 border of stabilized sand and low plant diversity; the middle-dune, characterized by high but 144 patchy plant species diversity and $40-60 \%$ bare sand cover; and the back-dune, characterized by 145 total woody plant cover (Fig. 1). In addition to these zones we will also refer to the front of the 146 fore-dune, or the seaward border of the fore-dune where embryo-dunes (Cowles 1899) form and

147 transition areas between major vegetation zones. To develop a site description of the plant 148 community we estimated the change in species cover (plant zonation) and species elevation 149 (plant elevation) across zones.

150 The plant zonation was assessed by quantifying the vegetation along $120 \mathrm{~m}$, walking parallel to 151 the coast-line, in each of four major dune zones: (1) the embryonic fore-dune, (2) the top fore152 dune on the first ridge of the dune formation, (3) the middle-dune with high plant species 
153 richness and bare substrate, and (4) the back-dune dominated by woody plants. In each zone, we

154 ran a transect line, starting from a random point, parallel to the shoreline and every $2 \mathrm{~m}$ placed a

$1550.5 * 0.5 \mathrm{~m}$ sampling quadrat subdivided into a $255 * 5 \mathrm{~cm}$ sampling grid to estimate plant

156 species cover and unvegetated substrate cover. Sixty quadrats were sampled per zone. We

157 characterized species diversity for each zone with the Shannon diversity index (H). All plant

158 species, after first introduction, will be referred to by genus names.

159 Plant elevation has been estimated by a correlative approach to support the conspicuous feature

160 of plants on the fore- and middle-dunes that generally occur on elevated sand mounds. Since

161 sand in these zones is mobile and windblown, we hypothesized that these mounds were created

162 by the presence of plants rather than plant establishment on transient dune features (Cowles

163 1899). We used an auto level and stadia rod to quantify the elevation of plants in each zone $(\mathrm{n}=$

164 20/zone) and bare sand adjacent to (25-cm away) each plant. In each zone we selected 20 adult

165 individuals of the most common plant species randomly, measured their elevation and the

166 elevation of unvegetated sand 10-20 cm away. Plant and adjacent sand elevation differences

167 were calculated, tested for homogeneity of variances with Cochran's test, transformed as

168 necessary (Underwood 1997) and analyzed by species with a one-way ANOVA, using the

169 statistical package GMAV (Underwood and Chapman 1998), and by a zone x plant ANOVA for

170 Armeria pungens, the only species with an inconsistent effect across zones.

172 We performed a foundation species removal experiment to test the hypothesis that foundation

173 dune plants bind sand and build the dune habitat, as well as to quantify secondary succession. In

174 each of the three major dune zones in March 2012, we marked the corners of 24 randomly placed 
$1751 * 1 \mathrm{~m}$ plots each separated by at least $10 \mathrm{~m}$. Within each zone, each plot was individually

176 labeled and then randomly assigned to one of three treatments: (1) controls, (2) total species

177 removal, or (3) procedural controls $(n=8 /$ treatment/zone). The 4 corners of each plot were

178 marked with $2 \mathrm{~cm}$ diameter rebar driven to refusal into the sand and cut to initially extend 10-15

$179 \mathrm{~cm}$ above the sand surface. Control plots were otherwise untouched. In plant removal replicates,

180 plots were perimeter trenched to $30 \mathrm{~cm}$ with straight edged shovels and all vegetation in the plots

181 was sprayed weekly for three weeks with a systemic herbicide (Roundup, Monsanto) until all

182 vegetation was dead. Dead above ground vegetation was left to simulate natural death, so to 183 evaluate the consequences of the lack of activity in terms of erosion. Roundup is widely used in 184 ecological research, has localized effects if plots are trenched to avoid translocation outside of 185 the target area, and we have used it successfully in the past in shoreline habitats (Bertness and 186 Hacker 1994). Procedural controls were trenched, but not herbicided.

187 Surface Elevation Table (SET) posts (Cahoon et al. 2000) modified for experimental replication 188 were installed in the center of all plots to measure sand erosion/accretion as a function of the 189 presence/absence of foundation species and dune zone. A $2 \mathrm{~cm}$ diameter rebar rod was driven to 190 refusal in the center of each plot, cut $10-15 \mathrm{~cm}$ above the sand surface and fitted with a $30 \mathrm{~cm}$ 191 long horizontal PVC bar with four evenly spaced locations to measure the height of the sediment 192 (see Brisson et al. 2014). Elevations were taken in October and March of each year at each SET 193 post for three years. Corner post heights were simultaneously measured to supplement SET data 194 and assess spatial patterns in sand erosion/accretion. Sediment height (the sand 195 erosion/deposition balance) data were analyzed with a two-way ANOVA of zone and treatment, 196 both considered as orthogonal fix factors, followed by post-hoc testing (SNK test). 
197 In the spring of 2013, we began monitoring temperature after noting apparent summer heat death

198 of some high middle-dune plants during the first year of this experiment. We deployed 24

199 thermistors (Econorma S.a.s. FT-800/System) to plots of this first experiment ( $\mathrm{n}=8 /$ dune zone),

200 attaching them under the canopy in control plots and plant removal plots with wire staples. This

201 allowed us to quantify plant heat exposure during the summer, and quantify differences between

202 control and removal treatments. Thermistors were left in the field from the mid-June until the

203 first week of September 2013 measuring temperature hourly. We took into account the data

204 between 01:30 a.m. and 05:30 a.m. and between 13:30 p.m. and 17:30 p.m. to estimate the

205 lowest and the highest daily temperature, respectively. The average of these temperature ranges

206 gave us mean minimum (Min) and mean maximum temperatures (Max) for each zone and

207 treatment. Temperature was analyzed with a three-way ANOVA considering zone, range (Min vs

208 Max), and treatment (removal vs control) as orthogonal and fix. A one-way ANOVA was used to 209 analyze mean maximum temperature by zone.

\section{Reciprocal species removal experiment (Inter-specific plant interactions)}

211

212

213

214

215

216

217

218

219

To test the hypothesis that inter-specific plant interactions shifted from facilitative to competitive across the sand dune, being especially important in the middle-dune, we performed reciprocal species removal experiments in all dune zones with dominant species pairs (see plant zonation).

On the fore-dune, we chose Armeria (sea rose) and Lotus cytisoides; in the middle-dune we chose Armeria, Lotus, and Carpobrotus acinaciformis (ice plant); and in the back-dune, we chose Armeria, Carpobrotus, and Pinus spp. (Pinus halepensis and Pinus pinea). For each species pair in each zone, we located $240.5 * 0.5 \mathrm{~m}$ plots with mixtures of the two target species. All plots were marked with numbered rebar corner posts driven to refusal into the sand and labeled with a unique numbered plastic tag. For each zone and species pair (species a and b), we 
220 randomly assigned control plots, "species a" removal plots, and "species b" removal plots $(\mathrm{n}=$

$2218 /$ treatment/species pair/dune zone). Species assigned for removal were pulled, manually when

222 possible, with minimal disturbance. Treatments were maintained monthly as needed for two

223 years. During this time, plots were photographed in the spring and fall of each year and analyzed

224 for percent plant cover. The height of the corner posts was also measured to quantify sand

225 deposition/erosion. Plant cover was analyzed by zone with a two-way ANOVA, only

226 Carpobrotus data were Sqrt $(\mathrm{X}+1)$ transformed, to meet the assumption of homoscedasticity.

227 Separate ANOVAs were run for each species at 12 and 18 months, to accommodate the loss of

228 plots to sand burial over time. For the same reason, we also analyzed plant cover and sand

229 deposition on plot plant cover data pooled by zone with a t test and plant $\mathrm{x}$ sediment cover with

230 linear regression.

232 In October 2013, sand under plants and in adjacent bare sand $>25 \mathrm{~cm}$ from plants, in all dune zones, have been sampled to examine the distribution of dune plant seeds and test the hypothesis that like sand, seeds are deposited and trapped under adult plants. This was done after the summer when seed dispersal and germination was most pronounced on the dune (Bakker et al. 2008). In each zone (fore, middle and back) we sampled sand under and adjacent to the most common plants in each zone by taking $100 \mathrm{ml}$ surface sand samples $(1 \mathrm{~cm}$ deep; $\mathrm{n}=$ 10/species/habitat/zone). Samples were returned to the laboratory and sorted under a dissecting microscope. Seed density was analyzed with an experimental treatment (under and adjacent to adult plants) one-way ANOVA separately by zone and on conspecific seeds of the target plant

241 and seeds of all other plants combined. 
242 Seedling survivorship across the dune has been examined in order to test the hypothesis that

243 seedling survivorship increased with dune elevation and association with adult plants, we marked

244 natural seedlings in all dune zones that were under adult plants and in bare sand $>30 \mathrm{~cm}$ from an

245 adult plant. 450 seedlings were marked and monitored monthly for survivorship over three

246 seasons. Seedling survivorship was analyzed with a non-parametric log rank test to compare

247 survival among zones (fore vs middle vs back) and species survival by location (next to adult vs

248 adjacent bare sand). In both cases the whole follow up period was taken into account (Bland and

249 Altman 2004) and a $\chi^{2}$ test was done on the log rank data of $\operatorname{Ln}(\mathrm{X}+1)$ transformed Armeria 250 seedling data.

251 A seed transplant experiment with the 5 most common Badesi sand dune plants (Armeria, Lotus,

252 Carpobrotus, Cakile maritima, and Pancratium maritimum) was performed to examine the

253 hypothesis that seed supply is a determinant of the distribution and abundance of plants across

254 the dune. For each species, we collected dehiscing seed heads and dissected out and separated

255 the seeds of each species. We then sorted them into aliquots of 4-10 seeds depending on species

256 seed availability and placed them by species into polyester mesh bags that would retain the

257 seeds, but would allow germination and seedling growth. For each species we planted 21 seed

258 bags in each zone (fore, middle and back) under conspecific adults and in unvegetated sand $>30$

$259 \mathrm{~cm}$ from adult vegetation and marked their location with color-coded wire markers. We

260 monitored seed transplants weekly for germination and seedling survivorship for three months.

261 Germination and seedling survivorship were analyzed separately by species with non-parametric

$262 \log$ rank data, using a $\chi^{2}$ test.

263 We also transplanted seeds of Pancratium in mesh bags $(\mathrm{n}=10)$, loose in the sand $(\mathrm{n}=10)$, and

264 loose in the sand covered on the sand surface with nylon mesh $(2 \mathrm{~mm} \mathrm{mesh,} 5 * 5 \mathrm{~cm}$ cover 
265 pinned to the sand surface with garden fabric staples; $\mathrm{n}=10$ ) to test the hypothesis that loose

266 seeds were eroded away on the fore-dune. We only did this experiment in the fore-dune since the

267 fore-dune was the only zone that showed significant erosion. Seed species were marked and

268 identified by color-coded wires $(2 \mathrm{~mm})$. All seeds were planted three $\mathrm{cm}$ below the sand surface.

269 We monitored these transplants for germination and survivorship weekly for the first three

270 months and monthly for one year. Germination and seedling survivorship data were analyzed

271 with a non-parametric log rank data, using a $\chi^{2}$ test.

273 During the first year we noticed that in the summer months, temperatures in the middle and

274 back-dune, protected from on shore winds by the fore-dune berm, were extremely high and 275 coincided with the death of the Carpobrotus at high dune elevations. To examine the hypothesis that shading would enhance the dominance of Carpobrotus, we quantified the long-term effect of shading on the Badesi dune as a proxy for high temperature impacts. In February 2015, we quantified shaded and unshaded vegetation adjacent to boardwalks $(1.5 \mathrm{~m}$ wide, elevated $50 \mathrm{~cm}$ over the substrate) perpendicular to the shoreline that extended from the fore-dune to the highest point of the back-dune, and $4 \mathrm{~m}$ on both sides of the boardwalks. We hypothesized that shading by the boardwalk would decrease solar stress on Carpobrotus. We sampled 2 boardwalks that had been in place 5 years. At each boardwalk we quantified live and dead Carpobrotus \% cover in $0.5 * 0.5 \mathrm{~m}$ quadrats every $2 \mathrm{~m}$ from the beginning of the fore-dune to the back-dune. For analysis we excluded plots levels without Carpobrotus and pooled the data from adjacent and control plots. Dead/alive ratio of Carpobrotus \% cover and dead Carpobrotus \% cover were

286 Sqrt $(X+1)$ transformed to meet the assumptions of parametric statistics and analyzed with a 
289 The hypothesis that physical stress limits dune plant recovery across the dune was tested by 290 running a fully factorial experiment across all zones manipulating all combinations of nutrient

291 limitation (with $33 \mathrm{ml}$ of slow release Osmocote NPK pellets spread on them every 6 months and 292 without nutrient additions), water limitation (with 2 liters of tap water every 2-3 weeks and 293 without water additions) and substrate stability (with and without substrate stabilizing fish net 294 attached flush to the surface with wire staples). In each zone we located $720.5 * 0.5 \mathrm{~m}$ plots with 295 bare sand substrate. Every combination of nutrient, water, substrate limitations and controls were marked and labeled with numbered rebar corner posts $(n=8 /$ treatment combination/zone).

297 298 300

\section{Back-dune competitive release experiment}

It was not possible to do Pinus removal experiments similar to the reciprocal plant species removal experiments or foundation species removals in other zones because of the size of Pinus trees. Since the Badesi dune is a protected conservation area, removing entire Pinus trees would have been destructive and not permitted. A competitive release experiment was conducted, to test the hypothesis that Pinus domination of the terrestrial high dune border is due to competitive dominance, by removing large ( 2 m long) Pinus branches and estimated natural plant recruitment by following seed germination and cover in $1.5 * 1.5 \mathrm{~m}$ plots under Pinus canopies $(\mathrm{n}=10)$, where Pinus shading was alleviated by branch removal $(\mathrm{n}=10)$ and in areas where 
310 Pinus shading was removed but replaced by a similar level of shading by shade cloth $(\mathrm{n}=10)$, as

311 procedural controls. A central $0.5 * 0.5 \mathrm{~m}$ quadrat in each plot was monitored photographically

312 monthly for a year.

313 We also manipulated sediment in the Pinus plots described above, to test the hypothesis that

314 allellopathy contributes to the dominance of Pinus and Carpobrotus in the back-dune.

315 Allelopathy was suggested because in dense Pinus and Carpobrotus stands, natural substrate is

316 covered by Pinus needles and Carpobrotus leaves, but seedlings of all species are extremely rare

317 (Ceccherelli, personal observation). In $100 \mathrm{ml}$ plastic greenhouse seedling pots we planted seeds

318 of Armeria, Pancratium, and Lotus (plus no seed controls) with either 1) Pinus soil, 2) middle-

319 dune bare soil, 3) middle-dune Carpobrotus soil, 4) potting soil mixed with sand, 5) potting soil

320 with a $2 \mathrm{~cm}$ layer of Pinus needles and 6) potting soil with a $2 \mathrm{~cm}$ layer of Carpobrotus leaves (n

$321=10 /$ Pinus treatment/soil type) and scored them monthly for germination. Seed germination and

322 survivorship of Armeria, and Lotus were transformed with Ln $(\mathrm{X}+1)$ and all were analyzed by

323 ANOVA testing the interactions between Pinus treatment x soil type.

\section{RESUlts}

Site description

Elevational zonation of plants across the Badesi dune is striking (Fig. 2). The fore-dune has low plant richness and cover (35\%) and 65\% unvegetated sand cover. Armeria (sea rose), Otanthus maritimus (cotton weed) and Lotus (trefoil of the cliffs) are the numerically dominant plant

329 species on the fore-dune and all are clonally spreading, deep-rooted perennials. The width of the fore-dune varies at Badesi from 20-25 m. The middle-dune has over 28\% higher plant cover and 53\% higher species richness than the fore-dune, but still has considerable bare sand substrate 
332 (Fig. 1, 38\%). Armeria, Carpobrotus and Ephedra distachya (joint pine) are the most common

333 middle-dune plant species and are all clonally spreading perennials. The middle-dune is $\sim 30-35$

334 m wide.

335 The transition from the middle to back-dune is more gradual (Fig. 2). The seaward border of the

336 back-dune has the highest plant species richness on the dune, and is dominated by the ice plant,

337 Carpobrotus, a perennial succulent, that can be seen overgrowing other back-dune plants like

338 Pinus on the terrestrial border of the dune (33\%). At higher elevations of the back-dune, Pinus

339 dominates the landscape as a solitary evergreen species that has a prostrate morphology at lower

340 elevations, an arborescent morphology at higher elevations and an understory of bare substrate in

341 the dense Pinus canopy that dominates high elevations.

342 Substrate topography in relation to plants varied across the dune. In dune zones closest to the

343 water, plants were found on elevated sand mounds that decreased in elevation with distance from

344 the water, while in the back-dune, furthest from the water, plants were not associated with sand

345 mounds. On the front dune, Armeria and Otanthus were found on sand mounds $53 \pm 2.16 \mathrm{~cm}$

346 (mean $\pm \mathrm{SE}$ ) and $56 \pm 2.51 \mathrm{~cm}$ higher than adjacent substrate, respectively. For the front dune,

347 the one-way ANOVA did not reveal any significant difference between the two species $\left(\mathrm{F}_{1,38}=\right.$

$3480.36 \mathrm{p}>0.05)$. On the fore-dune, Lotus and Armeria were similarly found on mounds $17 \pm 4.64$

349 and $24 \pm 1.92 \mathrm{~cm}$ high, respectively, and no significant effect was detected with the ANOVA

$350\left(\mathrm{~F}_{1,38}=2.07 \mathrm{p}>0.05\right)$. In contrast, in the middle-dune, Armeria, Carpobrotus, Lotus, Helicrysum

351 microphyllum and Ephedra were found on smaller sand mounds $22 \pm 1.47,12 \pm 2.06,11 \pm 1.06$,

$35216 \pm 1.27$, and $12 \pm 2.48 \mathrm{~cm}$ high, respectively. In this zone the difference among species was

353 significant $\left(\mathrm{F}_{4,95}=7.51 \mathrm{p}<0.0001, \mathrm{SNK}\right.$ : Armeria $>$ all others $)$. Armeria, a robust perennial

354 shrub, was found on higher sand mounds than all other species. One-way ANOVA on Armeria 
355 revealed differential Armeria sand binding by zone $\left(\mathrm{F}_{3,76}=111.36 \mathrm{p}<0.0001\right.$, SNK: front $>$ fore

356 top $=$ middle $>$ back). In the back-dune, buffered from winds and sand transport by the lower

357 dune zones, Armeria $=9 \pm 1.65 \mathrm{~cm}$, Carpobrotus $=4 \pm 1.31 \mathrm{~cm}$, Pinus $=4 \pm 2.76 \mathrm{~cm}$, Acacia

358 cyanophylla $=0 \pm 3.8 \mathrm{~cm}$, and Juniperus spp. (Juniperus macrocarpa and Juniperus phoenicea)

$359=-2 \pm 4.72 \mathrm{~cm}$ were not found on elevated locations and there were no significant species effects

$360\left(\mathrm{~F}_{4,95}=1.93 \mathrm{p}>0.05\right)$.

Removing foundation species had different effects across zones (Fig. 3). The two way ANOVA revealed a significant zone $x$ treatment interaction $\left(F_{4,63}=2.67 \mathrm{p}<0.05\right)$. In the fore-dune, foundation species removal led to sand erosion of $>2 \mathrm{~cm} / \mathrm{year}$, in contrast to control and procedural control plots that had annual sand accretion rates of $>4 \mathrm{~cm} /$ year (Fig. $3, \mathrm{p}<0.05$, SNK test fore: removal $<$ procedural control $=$ control). Sand erosion in the fore-dune foundation species removal plots was dramatic and led to the collapse of the fore-dune edge in just two years. When foundation species were removed, erosion on the seaward edge corner posts increased over $60 \%$ (compared to procedural control and control plots) leading to an amount of sand dispersion of $-2.8 \pm 1.6 \mathrm{~cm} /$ year (Fig. 3).

In the middle-dune, sediment level variation resulted in net sand accretion that occurred in all treatments (Fig. 3, p < 0.05, SNK test: fore $=$ back $<$ middle), but was nearly twice as high in control and procedural control plots with live vegetation to bind and trap sand than in removal plots (SNK middle: removal $<$ procedural control $=$ control $)$. middle-dune plots with foundation species (Fig. 3). Sand accretion in the back-dune was also 
377 similar among foundation removal, control and procedural control treatments (Fig. 3, p $<0.05$,

378 SNK back: removal $=$ procedural control $=$ control). In all treatments, annual accretion was $<1$

$379 \mathrm{~cm} /$ year and when foundation species were removed there was no sand accretion.

380 Mean minimum temperature (Min) did not differ among treatments or zones (fore $18.73 \pm 0.45^{\circ}$

$381 \mathrm{C}$ and $18.50 \pm 0.4^{\circ} \mathrm{C}$, middle $19.11 \pm 0.28^{\circ} \mathrm{C}$ and $19.12 \pm 0.18^{\circ} \mathrm{C}$, back $16.59 \pm 0.77^{\circ} \mathrm{C}$ and

$38217.07 \pm 0.87^{\circ} \mathrm{C}$ for removal and control, respectively; $\mathrm{F}_{2,228}=1.77 \mathrm{p}>0.05$ for the interaction

383 zone $\mathrm{x}$ temperature range $\mathrm{x}$ treatment). In contrast, mean maximum temperature (Max) differed

384 among zones (fore $33.73 \pm 1.40^{\circ} \mathrm{C}$ and $32.83 \pm 2.46^{\circ} \mathrm{C}$, middle $41.86 \pm 2.74^{\circ} \mathrm{C}$ and $38.31 \pm$

$3851.34^{\circ} \mathrm{C}$, back $44.89 \pm 3.61^{\circ} \mathrm{C}$ and $40.26 \pm 3.45^{\circ} \mathrm{C}$ for removal and control, respectively; $\mathrm{F}_{2,114}=$

$38639.85 \mathrm{p}<0.0001, \mathrm{SNK}$ : fore $<$ middle $=$ back $)$ peaking in back zone removal treatments $\left(\mathrm{F}_{1,114}=\right.$

$38710.72 \mathrm{p}<0.002, \mathrm{SNK}$ : Removal $>$ Control). Maximum temperatures peaked around $70^{\circ} \mathrm{C}$, and

388 averaged $45^{\circ} \mathrm{C}$ in the back-dune removal plots, $5^{\circ} \mathrm{C}$ higher than when vegetation was present.

390

391

392

393

394

395

396

397

398
Reciprocal species removal experiments initially revealed significant inter-specific interactions

(Fig. 4). Over time, however, these interactions were lost due to sand burial and erosion

disturbance, particularly in the fore and middle-dune zones as evidenced by a decrease in plant

cover over time in the species interaction plots (Fig. 4, middle $t=-3.84$ and $p<0.001, t$ test).

After 18 months, $22 \%$ of the middle-dune reciprocal species interaction plots had been

completely lost due to sand burial, and an additional $10 \%$ of the plots were still recognizable but almost totally buried, while no plots were lost in the fore or back-dune. To analyze this experiment, we ran separate two-way ANOVAs for each species after 12 months and 18 months of treatments, taking into account species interaction (comparison of each pair in which the 
399 species is involved) and treatment (reciprocal species removal vs control) as orthogonal and

400 fixed factors. Insignificant interaction $p$ values will always refer to the last sampling date (18

401 months). In the fore-dune after 6, 12, and 18 months, there was no evidence of reciprocal effects

402 between Armeria and Lotus (Fig. 4, interaction x treatment $F_{4,70}=1.96 \mathrm{p}>0.05$ and $\mathrm{F}_{2,42}=2.27 \mathrm{p}$

$403>0.05$, respectively).

404 In the middle-dune, after one year of treatment, Carpobrotus cover increased in both pairs where

405 Armeria and Lotus were removed, but after two seasons this effect was no longer apparent (Fig.

4064 , treatment $\mathrm{F}_{3,56}=12.12 \mathrm{p}<0.03$, SNK reciprocal species removal $>$ control at 12 months,

407 interaction $x$ treatment $F_{3,56}=1.23 \mathrm{p}>0.05$ at 18 months). At the same time, there was no

408 evidence of interactions affecting Armeria or Lotus (Fig. 4, interaction x treatment $\mathrm{F}_{4,70}=1.96 \mathrm{p}$

$409>0.05$ and $F_{2,42}=2.27 \mathrm{p}>0.05$, respectively). In all the inter-specific interaction plots in the

410 middle-dune there was, over time, a general decrease in plant cover associated with sand burial

411 disturbance (Fig. 4).

412 In the back-dune sand burial was not prevalent, but a summer die off of Carpobrotus was seen

413 every year (see below). After 12 months Armeria cover decreased in absence of both

414 Carpobrotus and Pinus but at 18 months this pattern was no longer apparent (Fig. 4, interaction $\mathrm{x}$

415 treatment $\mathrm{F}_{4,70}=3.31 \mathrm{p}<0.02$, SNK test for both Back pairs: reciprocal species removal $<$

416 control at 12 months, $F_{4,70}=1.96 \mathrm{p}>0.05$ at 18 months). While, after one year of removal, the

417 opposite was found for Carpobrotus, whose cover has increased in the absence of both Armeria

418 and Pinus, but after another two seasons of observation this growth was no longer detectable

419 (Fig. 4, treatment $\mathrm{F}_{3,56}=12.12 \mathrm{p}<0.03$, SNK reciprocal species removal $>$ control at 12 months,

420 interaction $\mathrm{x}$ treatment $\mathrm{F}_{3,56}=1.23 \mathrm{p}>0.05$ at 18 months). Reciprocal removal of Pinus in the 
421 back-dune did not reveal significant species interactions (Fig. 4, interaction $\mathrm{x}$ treatment $\mathrm{F}_{1,28}=$ $4220.18 \mathrm{p}>0.05)$.

424 Seeds of the most common dune plants were most abundant under adult plants independent of 425 species identity and dune zone (Fig. 5). For each zone, we performed a three-way ANOVA

426 considering the species, the substrate (under adult vs bare sand) and the seeds category

427 (conspecific vs other seeds) all as orthogonal and fixed factors. We will present only the factors 428 and/or the interactions that were significant (complete results at Table S1).

429 On the front of the fore-dune, seeds of Armeria and Otanthus were almost exclusively found 430 under conspecific adults, whereas the seeds of other species were rare and not found associated 431 with adult plants (Fig. 5, substrate $x$ seeds interaction $F_{1,72}=6.56 \mathrm{p}<0.02$ ). On the top of the 432 fore-dune, seeds of Armeria were more common under Armeria adults than in nearby bare sand, 433 but for Lotus and Pancratium, seeds of conspecifics were just as common in bare sand than 434 under adults (Fig. 5). For Lotus and Pancratium, conspecific seeds were equally distributed 435 under and away from adults, but seeds of other species were significantly more common under 436 Lotus and Pancratium than in adjacent bare sand (Fig. 5, species x seed category interaction, $437 \mathrm{~F}_{2,108}=4.23 \mathrm{p}<0.02$ and species $\mathrm{x}$ substrate $\mathrm{x}$ seeds category $\mathrm{F}_{2,108}=3.45 \mathrm{p}<0.04$, 438 respectively).

439 In the middle-dune, Armeria seeds were more common under Armeria adults than in adjacent 440 bare sand, but seeds of other species were not (Fig. 5), while for Carpobrotus, conspecific seeds 441 were rare, but seeds of other species were more than an order of magnitude more abundant under 442 Carpobrotus than in bare sand (Fig. 5, species $\mathrm{x}$ substrate $\mathrm{x}$ seeds interaction, $\mathrm{F}_{1,72}=12.59 \mathrm{p}=$ 
443 0.0007). In the back-dune, Armeria seeds were 20 times more common under conspecifics than

444 in adjacent bare sand, while for Carpobrotus, seeds of other species were significantly more

445 abundant under Carpobrotus than in adjacent bare substrate (Fig. 5, species x substrate x seeds

446 interaction $\left.\mathrm{F}_{1,72}=8.34 \mathrm{p}<0.006\right)$.

447 The survivorship of marked seedlings was analyzed with a log rank test comparing the survival

448 of the seedlings of each species comparing the proximity with adult (next to adult vs adjacent

449 bare sand) and of the seedlings in general pooled in three groups corresponding to the three

450 zones (fore vs. middle vs. back seedlings), on the times (weeks) of survival events. The percent

451 of seedlings survivorship increased dramatically with dune zone elevation but was not affected

452 by neighboring plants (Table $\mathrm{S} 2, \mathrm{p}<0.05, \chi^{2}$ ). In the fore-dune, no Lotus seedlings survived

453 (independent of the proximity to adult neighbors), no Pancratium seedlings survived on bare

454 sand, and less than 5\% of Pancratium seedlings survived next to adults, but this result was not

455 significant $\left(\mathrm{p}>0.5, \chi^{2}\right)$. In the middle zone only $5 \%$ of Lotus seedlings survived with or without

456 adult neighbors $\left(\mathrm{p}>0.5, \chi^{2}\right)$, while for Armeria $25 \%$ of marked seedlings in bare sand survived,

457 nearly three times $(10 \%)$ the number of seedlings that survived next to adults $\left(p<0.025, \chi^{2}\right)$. No

458 Pancratium seedlings survived. In the back-dune survivorship of Armeria and Carpobrotus

459 seedlings was over $80 \%$, far higher than any other zone, and was not influenced by the presence

460 or absence of neighbors (Table S2).

462 Of the six dune plant species seeds used in transplant studies, three species, Pancratium, Lotus, 463 and Cakile germinated. Only 2 and 3 Armeria and Otanthus germinated from back and fore-dune 464 planted seeds respectively, while Astragalus thermensis and Carpobrotus did not germinate in 
465 any location or treatment. For each of the three species that had sufficient germination, we

466 compared the germination and survival in each of the three zones. $30-40 \%$ of Pancratium seed

467 transplants germinated, but germination was similar among zones $\left(p>0.1, \chi^{2}\right)$. Survivorship of

468 seedlings from the seed transplant experiment showed that all species had the highest

469 survivorship in the back-dune, but this pattern was only significant for Pancratium, which had

470 the highest sample size (Fig. $6, p<0.005, \chi^{2}$ ). Less than $10 \%$ of the transplanted Lotus seeds

471 germinated and Lotus, found ubiquitously across the dune, had higher germination in the back-

472 dune, and lowest germination in the middle-dune (Fig. $6, p<0.025, \chi^{2}$ ), while survivorship did

473 not differ among zones $\left(\mathrm{p}>0.5, \chi^{2}\right)$. For Cakile, a pioneer species found naturally in the fore and

474 middle-dune, $12-18 \%$ of transplanted seeds germinated and among zones had higher germination

475 in the middle than in fore and back-dune (Fig. $6, \mathrm{p}<0.05, \chi^{2}$ ). Survivorship, however, did not

476 differ among zones $\left(\mathrm{p}>0.5, \chi^{2}\right)$.

477 In the fore-dune seed stabilization experiment with Pancratium, germination and survivorship

478 were analyzed comparing germination and survival among the three treatments (seeds in bags vs

479 loose seeds vs. loose seeds with net covers). Due to erosion, germination was highest in the

480 bagged seed treatment, second highest in the seed treatment with stabilized substrate (net cover),

481 and lowest in the loose seed treatments (Fig. S1, $p<0.005, \chi^{2}$ ). The difference in germination

482 between loose seeds and the secured seed treatments was $>10 \%$, suggesting that sand erosion in

483 the fore-dune can lead to seed loss. Seedling survivorship in this experiment was similar among

484 stabilization treatments $\left(\mathrm{p}>0.25, \chi^{2}\right)$. 
486 Analysis of Carpobrotus cover data (dead/alive ratio) adjacent to and $2 \mathrm{~m}$ away from the shade

487 of boardwalks revealed almost twice as much live Carpobrotus cover under the shade of the

488 boardwalks $(46 \pm 3.24 \%)$ than in adjacent unshaded habitats $\left(25 \pm 2.84 \% ; \mathrm{F}_{1,190}=5.58 \mathrm{p}<0.02\right)$.

489 There was also nearly $10 \%$ more dead Carpobrotus in unshaded habitats $(16 \pm 1.76 \%)$ than

490 under the shade of boardwalks $\left(7 \pm 1.10 \%, \mathrm{~F}_{1,190}=18.76 \mathrm{p}<0.0001\right)$.

Experimentally manipulating water availability, nutrient availability and substrate stability across dune zones (fore, middle and back) in a fully factorial 2 year experiment at a $0.5 * 0.5 \mathrm{~m}$ spatial 494 scale revealed that these factors, long thought to be critical to sand dune plant communities, had no effect on plant recovery, as evidenced by a two-way ANOVA (Table S3). However, recovery increased from the fore to the back-dune (Fig. 7, Table S3, SNK fore $<$ mid $<$ back).

Natural plant recruitment was not observed under Pinus, irrespectively of canopy removal treatments. However, germination of experimentally planted seeds under Pinus occurred, although it was generally lower in control plots, especially for Armeria and Lotus (Fig. 8). We ran a two-way ANOVA by species with canopy treatment and soil type as fixed and orthogonal factors. Under the Pinus canopy, Armeria seeds attracted small animals as they were often removed or eaten. Armeria germination, however, was significantly higher in the Pinus removal treatment in middle-dune soil, and very little germination occurred in any soil type under Pinus canopy and in procedural control plots (Fig. 8, canopy treatment $\mathrm{x}$ soil type interaction, $\mathrm{F}_{12,126}=$ $2.54 \mathrm{p}<0.005)$. Pancratium and Lotus germination was not influenced by the Pinus treatment

$507\left(\mathrm{~F}_{2,126}=2.11 \mathrm{p}>0.05\right.$ and $\mathrm{F}_{2,126}=0.79 \mathrm{p}>0.05$, respectively $)$, but they were significantly 
508 affected by soil type (Fig. 8, $F_{6,126}=5.02 \mathrm{p}=0.0001$ and $\mathrm{F}_{6,126}=7.06 \mathrm{p}<0.0001$, respectively),

509 even if, for both species, there were no significant post hocs comparisons. The interaction Pinus

510 treatment $x$ soil type was not significant for both species $\left(F_{12,126}=0.96 p>0.05\right.$ and $F_{12,126}=0.84$

$511 \mathrm{p}>0.05$, respectively).

\section{DISCUSSION}

514 Our results, testing the basic assumptions of sand dune community organization, generally support a hierarchical model of sand dune community organization and confirm many, but not all

516 of the assumptions of early descriptive and correlative studies on the organization of these

517 communities. Experimental examination of community assemblages typically has not upheld the

518 findings of earlier correlative conclusions. For example, rocky intertidal, salt marsh, kelp forest, 519 and coral reef community dynamics once thought to be driven by physical forces (e.g. Odum 520 1953, Lewis 1964, Mann 1982), were later shown to be regulated strongly by interactions

521 between physical and biological factors once community level experiments were carried out 522 (Dayton 1971, Estes and Palmisano 1974, Bertness and Ellison 1987). Our results suggest that 523 fore-dune foundation species are responsible for binding, stabilizing and maintaining sand dune 524 communities, and that inter-specific plant interactions occur across the dune, but are generally 525 overshadowed by physical stresses, particularly sand burial in the middle-dune. Additionally, 526 they indicate that while physical stresses limit plant distributions across the dune, their impacts 527 are largely stochastic, except in the back-dune where competitively dominant woody plants 528 competitively displace other sand dune plants. In the back-dune species removal plots, the most 529 conspicuous trend over time was the decrease in the cover of Carpobrotus during summer. This 
530 left large areas of dead, desiccated Carpobrotus dominating the seaward border of the back-dune

531 at the end of the summer. Since Carpobrotus death occurs almost exclusively in summer

532 (Cusseddu, personal observation), mortality at high dune elevations appears to be driven by heat

533 and desiccation from direct sun exposure leaving the desiccated plants marking their initial

534 distribution.

535

Biogenic Communities, Foundation species and Hierarchical organization

536 Like most communities in physically and/or biologically stressful habitats, the Badesi sand dune

537 plant community is dependent on foundation species that ameliorate stress and facilitate

538 community development (Angelini et al. 2011). The front, fore and middle-dune dominant

539 plants occur on elevated sand mounds that appear to be actively trapped by passive deposition

540 of wind-blown sand. Our foundation plant species removals reveal that plant species on the fore-

541 dune bind and stabilize sand, building the habitat that supports all the dune plants living at higher

542 elevations, making them foundation species-dependent (Fig. 3). Without habitat-modifying

543 foundation species that initially colonize potential fore-dune habitats, sand dune plant

544 communities would not develop or be maintained. Biogenic communities that are dependent on

545 foundation species often display this type of hierarchical organization (Bruno and Bertness 2001,

546 Angelini et al. 2011) and include salt marshes (Angelini et al. 2011), terrestrial forests (Ellison et

547 al. 2005), seagrass meadows (Duarte et al. 2000), as well as smaller scale associations within

548 communities (Angelini and Silliman 2014). This common dependency of communities on

549 foundation species habitat modification needs to be incorporated into ecological theory (Bruno et

550 al. 2003). It is a major organizing force in community assembly, confirmed by the overwhelming

551 evidence that it is the template for communities in physically and biologically stressful habitats 
552 due to habitat amelioration and associational defenses, respectively (Bertness and Callaway

553 1994, Ellison et al. 2005, Crotty and Bertness 2015).

554

Seedling Recruitment

555 Sexual recruitment is generally problematic in physically- and biologically-stressful

556 communities like salt marshes (Pennings and Callaway 1996) and coral reefs (Hughes and

557 Jackson 1985). As a result, asexual reproduction and clonal growth play a leading role in the

558 community dynamics of such communities. Sexual recruitment is limited in Sardinian sand dune

559 plant communities exposed to severe substrate mobility and strong wind and salt spray exposure.

560 Dispersed seeds of dune plants were trapped near substrate stabilizing adult plants and were

561 uncommon in unvegetated substrate (Fig. 5). The survivorship of marked seedlings was low, but

562 generally increased from the fore to the back-dune and was higher when seedlings were

563 associated with adult plants than when on bare sand substrate without neighbors.

564 Field germination experiments with three common species had low germination rates and poor

565 survivorship in all zones except the back-dune. Seedlings of back-dune grew the best, but

566 suffered from desiccation, due to high temperature and herbivory (Fig. 6). Like in other stressful

567 environments, the low success of seed reproduction appears to lead to nurse plant effects (Franks

568 2003) and strong reliance of dune plants on clonal reproduction, particularly at low elevations

569 (Maun 1998). Nurse plant effects have been identified as a strong generator of pattern in sand

570 dune plant communities in general (Martinez 2003).

Competitive dominance

572 Pairwise quantification of the interaction of the numerically common plants in each dune zone

573 revealed that inter-specific plant competition was common across the dune landscape. In the 
574 middle-dune, however, burial disturbance over the 18-months time course of our experiments

575 revealed that, while inter-specific plant interactions occurred, their importance was transient and

576 not of long-term consequence in generating species distribution patterns. Rather, sand burial

577 disturbance limited the role of inter-specific competition and competitive displacement, but

578 promoted plant species diversity and coexistence in the middle-dune (Fig. 4). Similar results

579 have been found on rocky shores, intertidal boulder fields, mussel beds, salt marshes, and

580 grasslands (see Dayton 1971, Sousa 1979, Paine and Levin 1981, Bertness and Ellison 1987, and

581 Platt 1975, respectively). In the back-dune, where sand burial is less common, competitive

582 dominance by woody plants emerges as a major factor leading to competitive dynamics that

583 determine the prevalence of shrub and woody species like Pinus and Armeria and exclusion of

584 other dune species. Due to the dense Pinus canopy, germination of other middle-dune species is

585 precluded and in some cases soil type prevents seedling recruitment. Moreover, high summer

586 temperatures in the back-dune limit Carpobrotus competitive dominance, because it suffers

587 drying and summer die-off limiting its dominance, favoring Pinus.

While our inter-specific plant interaction experiments initially revealed significant interactions

(Fig. 4), sand burial, particularly in the middle-dune, was ultimately the most pervasive and

591 powerful driver of plant community patterns at lower dune elevations, rendering competitive dominance and facilitative interactions inconsequential. Thus, the same physical force that is responsible for building the dune, sand mobility, is responsible for plant mortality and diversity, particularly in the middle-dune. Burial in sand is recognized as a major aspect shaping the arrangement and composition of vegetation in coastal sand dune communities (Ranwell 1958, 
597 selective force in the evolution of seeds, in survivorship of seedlings and adult plants and, to a

598 larger scale, in zonation and succession of vegetation (Maun 1994 and 1998).

600 Our results reveal that sand dune plant communities are organized hierarchically and dependent 601 on the establishment of fore-dune foundation plants that bind sand above and belowground, 602 leading to sand dune initiation, development, and maintenance (Fig. 3). Without foundation plant 603 species, mechanisms such as sand binding, erosion, mobility, and burial act as barriers to plant 604 community development (Fig. 3) and are more pronounced than at higher elevations that are less 605 exposed to sand mobility. On the fore-dune, removing the foundation species led to habitat loss, while competitive and facilitative plant species interactions were not detectable due to sand

607 608 609 erosion and burial disturbance (Fig. 4). Manipulating physical factors thought to be critical in sand dune communities (i.e. water additions, nutrient additions, substrate stabilizations) in well replicated plots of all these factors alone and in combination also did not affect plant colonization at the small $0.25 \mathrm{~m}^{2}$ spatial scale manipulated, this does not mean that, at other scales, would not have an effect, or that water and nutrient availability are unimportant for the structure of dune communities. Seed and seedling success were also rare on the fore-dune suggesting that asexual clonal expansion and colonization was more common in the highly disturbed fore-dune habitat. This also suggests that disturbance on the fore-dune trumps all other biological and physical factors. Since all of these physical and biological factors have been shown to correlatively impact sand dune communities at regional spatial scales, our results imply that spatial scale is important in understanding process and pattern in sand dune ecosystems since they are so fundamentally shaped by disturbance processes and their interaction with foundation plant species that stabilize the substrate. 
620 Plant species cover and richness increased from $35 \%$ in the fore-dune to $63 \%$ in the middle-dune

621 (Fig. 2). Like the fore-dune, however, recovery from foundation removal was minimal, being

622 less than $1 \%$ in 3 years. Moreover, while the middle-dune initially revealed inter-specific plant

623 interactions, it is subjected to heavy sand burial that limited the role of species interactions, seed

624 germination (Fig. 6), and seedling success (Table S2). Therefore, frequent sand burial

625 disturbances have a large influence in the middle-dune zone on the community dynamics (Fig. $6264)$.

627 In the back-dune we see nearly $100 \%$ plant cover and the emergence of competitive dominants

628 (Fig. 1D and 2). On the seaward border of the high dune the Carpobrotus is common and

629 appears to be competitively dominant to middle-dune plant species, but, at higher dune

630 elevations, the evergreen Pinus competitively displaces most other dune plants, forming a back-

631 dune Pinus monoculture. Seedling germination and survivorship were higher in the back-dune

632 than at lower dune elevations (Fig. 6), as was the recovery of the species (Fig. 7). The

633 competitive dominance of Pinus in the back-dune was shown by a competitive release

634 experiment in which removing Pinus canopy in the back-dune lead to the success of important

635 foundation species such as Armeria, especially favored in the middle-dune soil (Fig. 8). In

636 general, however, seeds of plants characteristic of the middle and fore-dune planted in Pinus

637 zone showed a quite good capability of germination. This suggests that they are excluded from

638 the back-dune because Pinus acts as a physical barrier, having a dense prostrate morphology

639 (Fig. 8).

640

\author{
Conclusions
}


641 Our results are summarized in a conceptual model of the assembly rules of the Badesi sand dune

642 plant community (Fig. 9). The gradient of stress in this dune system acts crosswise, from land to

643 sea and back again, creating an area of aggregation of the various factors in the middle of the

644 dune, in which the living conditions are particularly difficult. It is for this reason that facilitation

645 mechanisms are determined among species, however, they are transient in nature due to high

646 instability. Physical stress on the vascular plants of the dune, including wind exposition, sand

647 scouring, and other stressors of terrestrial origins, decreases with increasing dune elevation

648 exposure. Conversely, the role of biological factors in shaping the dune plant community

649 increases with increasing dune elevation. These factors include inter-specific plant competition

650 and facilitation, increasing seedling recruitment and survival, and increasing herbivory. The

651 Badesi dune plant community is a biogenic community built and maintained by foundation plant

652 species that stabilize sand on the fore-dune. On the middle-dune, sand burial disturbance is the

653 dominant structuring force that limits the role of sexual recruitment and inter-specific

654 competition in structuring the middle-dune zone. In the back-dune, Carpobrotus and Pinus

655 competitively dominate all other dune plants, but high summer temperatures limit Carpobrotus

656 dominance in the back-dune, resulting in Pinus competitively dominating the back-dune

657 terrestrial border.

658 Ecosystems, like sand dunes, where the establishment of foundation species ameliorates stresses

659 allow community development that would not occur without foundation species. Coral reefs

660 (Hughes and Jackson 1985), salt marshes (Bruno and Bertness 2001), mangroves (Ellison and

661 Farnsworth 2001), seagrass (Duarte et al. 2000), and forest ecosystems (Ellison et al. 2005) have

662 all been explicitly or implicitly described as hierarchically organized systems. In all of these

663 ecosystems, once foundation species enabled community establishment, while other biotic 
664 factors like competition, recruitment, and trophic dynamics became important community

665 structuring forces (Bruno and Bertness 2001). These findings and their implications are

666 important for understanding community organization well enough to make it a more predictive

667 science and for conservation since they stress that managing, protecting, and restoring foundation

668 species should often be the first step in many conservation efforts, rather than focusing on

669 charismatic species.

670

\section{ACKNOWLEDGMENTS}

671 We would thank H. Chen, S. M. Crotty, E. Farris, R. S. Filigheddu, E. Suglia, T. Pettengill, M.

672 Bergland and S. Hagerty for discussion and comments, T. C. Coverdale, S. Pinna, S. Oliva, F.

673 Bulleri, L. Piazzi, J. Bernardeau, J. Boada for assistance with field and laboratory, S. Pisanu for

674 help identifying plants, S. Ramachandran for statistical advice and the mayor of Badesi, A. P.

675 Stangoni, for his support. This work was part of V. Cusseddu's PhD. 


\section{REFERENCES}

678 Acosta, A., M. L. Carranza, and C. F. Izzi. 2009. Are there habitats that contribute best to plant 679 species diversity in coastal dunes? Biodiversity and Conservation 18: 1087-1098.

680

681

682

683

684

685

686

687

688

689

690

691

692

693

694

695

Altieri, A. H., B. R. Silliman, and M. D. Bertness. 2007. Hierarchical Organization via a Facilitation Cascade in Intertidal Cordgrass Bed Communities. American Naturalist 169: 195-206.

Altieri, A. H., B. K. van Wesenbeeck, M. D. Bertness, and B. R. Silliman. 2010. Facilitation cascade drives positive relationship between native biodiversity and invasion success. Ecology 91: 1269-1275.

Angelini, C., A. H. Altieri, B. R. Silliman, and M. D. Bertness. 2011. Interactions among Foundation Species and their Consequences for Community Organization, Biodiversity and Conservation. BioScience 61: 782-789.

Angelini, C., and B. R. Silliman. 2014. Secondary foundation species as drivers of trophic and functional diversity: evidence from a tree-epiphyte system. Ecology 95: 185-196.

Bacchetta, G., A. Coppi, C. Pontecorvo, and F. Selvi. 2008. Systematics, phylogenetic relationships and conservation of the taxa of Anchusa (Boraginaceae) endemic to Sardinia (Italy). Systematics and Biodiversity 6: 161-174.

Bakker, J. P., L. G. Bravo, and A. M. Mouissie. 2008. Dispersal by cattle of salt marsh and dune species into salt marsh and dune communities. Plant Ecology 197: 43-54. 
696 Barbier, E. B., I. Y. Georgiou, B. Enchelmeyer, and D. J. Reed. 2013. The Value of Wetlands in 697 Protecting Southeast Louisiana from Hurricane Storm Surges. PLoSONE 8(3): e58715. 698 doi:10.1371/journal.pone.0058715.

699 Barbour, M. G., T. D. de Jong, and B. M. Pavlik. 1985. Marine beach and dune plant 700 communities. Pages 296-322 in Physiological ecology of North American plant communities. 701 B. F. Chabot and H. A. Mooney, editors. Chapman and Hall, New York.

702

Bertness, M. D., and A. M. Ellison. 1987. Determinants of Pattern in a New England Salt Marsh Plant Community. Ecological Monographs 57: 129-147.

Bertness, M. D., and R. Callaway. 1994. Positive interactions in communities. Trends in Ecology and Evolution 9: 191-193.

Bertness, M. D., and S. D. Hacker. 1994. Physical Stress and Positive Associations Among Marsh Plants. The American Naturalist 144: 363-372.

Bland, J. M., and D. G. Altman. 2004. The log rank test. BMJ 328: 1073.

Blondel, J., and J. Aronson. 1999. Biology and wildlife of the Mediterranean region. Oxford University Press, New York.

Brisson, C. P., T. C. Coverdale, and M. D. Bertness. 2014. Salt marsh die-off and recovery reveal disparity between the recovery of ecosystem structure and service provision. Biological Conservation 179: 1-5.

Bruno, J. F., and M. D. Bertness. 2001. Habitat Modification and Facilitation in Benthic Marine Communities. Pages 201-218. in Marine Community Ecology. M. D. Bertness, S. D. Gaines and M. E. Hay, editors. Sinauer Associates, Sunderland, Massachusetts, USA. 
717 Bruno, J. F., J. J. Stachowicz, and M. D. Bertness. 2003. Inclusion of facilitation into ecological

718 theory. Trends in Ecology and Evolution 18: 119-125.

719 Cahoon, D. R., P. E. Marin, B. K. Black, and J. C. Lynch. 2000. A method for measuring vertical 720 accretion, elevation, and compaction of soft, shallow-water sediments. Journal of Sedimentary 721 Research 70: 1250-1253.

722 Castanho de Toledo, C., C. J. Lortie, B. Zaitchik, and P. I. Prado. 2015. A meta-analysis of plant 723 facilitation in coastal dune systems: responses, regions, and research gaps. PeerJ 3:e768 724 https://dx.doi.org/10.7717/peerj.768.

725 Cowles, H. C. 1899. The Ecological Relations of the Vegetation on the Sand Dunes of Lake 726 Michigan. Geographical Relations of the Dune Floras. Botanical Gazette 27: 95-117.

727 Crotty, S. M., and M. D. Bertness. 2015. Foundation Species Expansion of Habitat Use and the 728 Realized Niches of Sympatric Species. Ecology. In press

Cushman, J. H., J. C. Waller, and D. R. Hoak. 2010. Shrubs as ecosystem engineers in a coastal 730 dune: influences on plant populations, communities and ecosystems. Journal of Vegetation

Dayton, P. K. 1971. Competition, Disturbance, and Community Organization: The Provision and 733 Subsequent Utilization of Space in a Rocky Intertidal Community. Ecological Monographs 734 41: 351-389. community. Ecological Monographs 45:137-159. 
737 Duarte, C. M., J. Terrados, N. S. R. Agawin, and M.D. Fortes. 2000. An experimental test of the 738 occurrence of competition among SE Asian seagrasses. Marine Ecology Progress Series 197: $739 \quad 231-240$.

740

741

742

743

744

745

746

747

748

749

750

751

752

753

754

755

756

757

Ehrenfeld, J. G. 1990. Dynamics and processes of barrier-island vegetation. Reviews in Aquatic

$$
\text { Sciences 2: 437-480. }
$$

Ellison, A. M., and E. J. Farnsworth. 2001. Mangrove Communities. Pages 424-442. In Marine Community Ecology. M. D. Bertness, S. D. Gaines and M. E. Hay, editors. Sinauer Associates, Sunderland, Massachusetts, USA.

Ellison, A. M., M. S. Bank, B. D. Clinton, E. A. Colburn, K. Elliott, C. R. Ford, D. R. Foster, B. D. Kloeppel, J. D. Knoepp, G. M. Lovett, J. Mohan, D. A. Orwig, N. L. Rodenhouse, W. V. Sobczak, K. A. Stinson, J. K. Stone, C. M. Swan, J. Thompson, B. Von Holle, and J. R. Webster. 2005. Loss of foundation species: consequences for the structure and dynamics of forested ecosystems. Frontiers in Ecology and the Environment 9: 479-486.

Estes, J. A., and J. F. Palmisano. 1974. Sea otters: Their role in structuring nearshore communities. Science 185: 1058-1060.

Everard, M., L. Jones, and B. Watts. 2010. Have we neglected the societal importance of sand dunes? An ecosystem services perspective. Aquatic Conservation: Marine and Freshwater Ecosystems 20: 476-487.

Fadda, L. 2016. ARPAS, IMC - Analisi periodiche. (online) Sar.sardegna.it. Available at: http://www.sar.sardegna.it/pubblicazioni/periodiche/reportannuali.asp (Accessed 13 May 2016). 
758 Fenu, G., M. Carboni, A. T. R. Acosta, and G. Bacchetta. 2013. Environmental Factors

759 Influencing Coastal Vegetation Pattern: New Insights from the Mediterranean Basin. Folia

$760 \quad$ Geobotanica 48:493-508.

761 Franks, S. J. 2003. Competitive and facilitative interactions within and between two species of 762 coastal dune perennials. Canadian Journal of Botany 81: 330-337.

763 Franks, S. J. 2003. Facilitation in multiple life-history stages: evidence for nucleated succession 764 in coastal dunes. Plant Ecology 168: 1-11.

765 Franks, S. J., and C. J. Peterson. 2003. Burial disturbance leads to facilitation among coastal 766 dune plants. Plant Ecology 168: 13-21.

767

768

769

770

771

772

773

774

775

776

Gemma, J. N., R. E. Koske, and M. Carreiro. 1989. Seasonal dynamics of selected species of VA mycorrhizal fungi in a sand dune. Mycological Research 92: 317-321.

He, Q., and M. D. Bertness. 2014. Extreme stresses, niches, and positive species interactions along stress gradients. Ecology 95: 1437-1443.

Hesp, P. A. 1991. Ecological processes and plant adaptions on coastal dunes. Journal of Arid Environments 21: 165-191.

Hughes, T. P., and J. B. C. Jackson. 1985. Population dynamics and life histories of foliaceous corals. Ecological Monographs 55: 141-166.

Huntzinger, M., R. Karban, and J. H. Cushman. 2008. Negative effects of vertebrate herbivores on invertebrates in a coastal dune community. Ecology 89: 1972-1980. 
777 Isermann, M. 2011. Patterns in Species Diversity during Succession of Coastal Dunes. Journal of

778 Coastal Research 27: 661-671.

779 Jones, C. G., J. H. Lawton, and M. Shachak. 1994. Organisms as ecosystem engineers. Oikos $780 \quad 69: 373-386$.

781 Lewis, J. R. 1964. The Ecology of Rocky Shores. English Universities Press, London, UK.

782 Lichter, J. 1998. Primary Succession and Forest Development on Coastal Lake Michigan Sand 783 Dunes. Ecological Monographs 68: 487-510.

784 Lichter, J. 2000. Colonization constraints during primary succession on coastal Lake Michigan 785 sand dunes. Journal of Ecology 88: 825-839.

786 Lortie, C. J., and J. H. Cushman. 2007. Effects of a directional abiotic gradient on plant 787 community dynamics and invasion in a coastal dune system. Journal of Ecology 95: 468-481.

788 Mack, R. N., and J. L. Harper. 1977. Interference in dune annuals: spatial pattern and 789 neighbourhood effects. Journal of Ecology 65: 345-363.

790 Maestre, F. T., R. M. Callaway, F. Valladares, and C. J. Lortie. 2009. Refining the stress791 gradient hypothesis for competition and facilitation in plant communities. Journal of Ecology 792 97: 199-205. 794 Press.

Martinez, M. L. 2003. Facilitation of seedling establishment by an endemic shrub in tropical coastal sand dunes. Plant Ecology 168: 333-345. 
797 Maun, M. A., and J. Lapierre. 1986. Effects of burial of sand on seed germination and seedling 798 emergence of four dune species. American Journal of Botany 73: 450-455.

799

800

801

802

803

804

805

806

807

808

809

810

811

812

813

814

815

816

Maun, M. A. 1994. Adaptation enhancing survival and establishment of seedlings on coastal dune systems. Vegetatio 111: 59-70.

Maun, M. A. 1998. Adaptations of plants to burial in coastal sand dunes. Canadian Journal of Botany 76: 713-73.

Maun, M. A., and J. Perumal. 1999. Zonation of vegetation on lacustrine coastal dunes: effects of burial by sand. Ecology Letters 2: 14-18.

Miller, T. E., E. S. Gornish and H. L. Buckley. 2010. Climate and coastal dune vegetation: disturbance, recovery, and succession. Plant Ecology 206: 97-104.

Morin, P. J. 2011. Community Ecology, Second Edition. Wiley Blackwell, Oxford, UK.

Odum, E. P. 1953. Fundamentals of Ecology. W. B. Saunders Company, Philadelphia, USA.

Olff, H., J. Huisman, and B. F. Van Tooren. 1993. Species dynamics and nutrient accumulation during early primary succession in coastal sand dunes. Journal of Ecology 81: 693-706.

Oosting, H. J., and W. D. Billings. 1942. Factors Effecting Vegetational Zonation on Coastal Dunes. Ecology 23: 131-142.

Paine, R. T., and S. A. Levin. 1981. Intertidal Landscapes: Disturbance and the Dynamics of Pattern. Ecological Monographs 51: 145-178.

Pennings, S. C., and R. M. Callaway. 1996. Impact of a Parasitic Plant on the Structure and Dynamics of Salt Marsh Vegetation. Ecology 77: 1410-1419. 
817 Platt, W. J. 1975. The Colonization and Formation of Equilibrium Plant Species Associations on

818 Badger Disturbances in a Tall-Grass Prairie. Ecological Monographs 45: 285-305.

819 Prisco, I., A. T. R. Acosta, and S. Ercole. 2012. An overview of the Italian coastal dune EU 820 habitats. Annali di Botanica 2: 39-48.

821 Ranwell, D. S. 1958. Movement of vegetated sand dunes at Newborough Warren, Anglesey.

822 Journal of Ecology 46: 83-100.

823 Sousa, W. P. 1979. Disturbance in Marine Intertidal Boulder Fields: The Nonequilibrium 824 Maintenance of Species Diversity. Ecology 60: 1225-1239.

825 Underwood, A. J. 1997. Experiments in ecology: their logical design and interpretation using 826 analysis of variance. Cambridge University Press.

827 Underwood, A. J., and M. G. Chapman. 1998. GMAV5 for Windows. Institute of Marine 828 Ecology, University of Sydney. 
TABLE 1. Objectives and corresponding tasks performed to develop our hypotheses.

\begin{tabular}{l|ll}
\multicolumn{1}{c|}{ Objective } & & \multicolumn{1}{c}{ Task } \\
Site description & - & Plant zonation \\
& & \\
\hline Hypothesis 1: Hierarchical & - & Plant elevation \\
organization & - & Temperature \\
& & \\
\hline & - & Reciprocal species removal experiment \\
Hypothesis 2: Stress & & survivorship, Seed transplant experiments) \\
gradient hypothesis & & \\
& - & Boardwalk shadow effect sampling \\
\hline $\begin{array}{l}\text { Hypothesis 3: Competitive } \\
\text { dominance }\end{array}$ & - Physical stress alleviation experiment \\
&
\end{tabular}


Figure 1

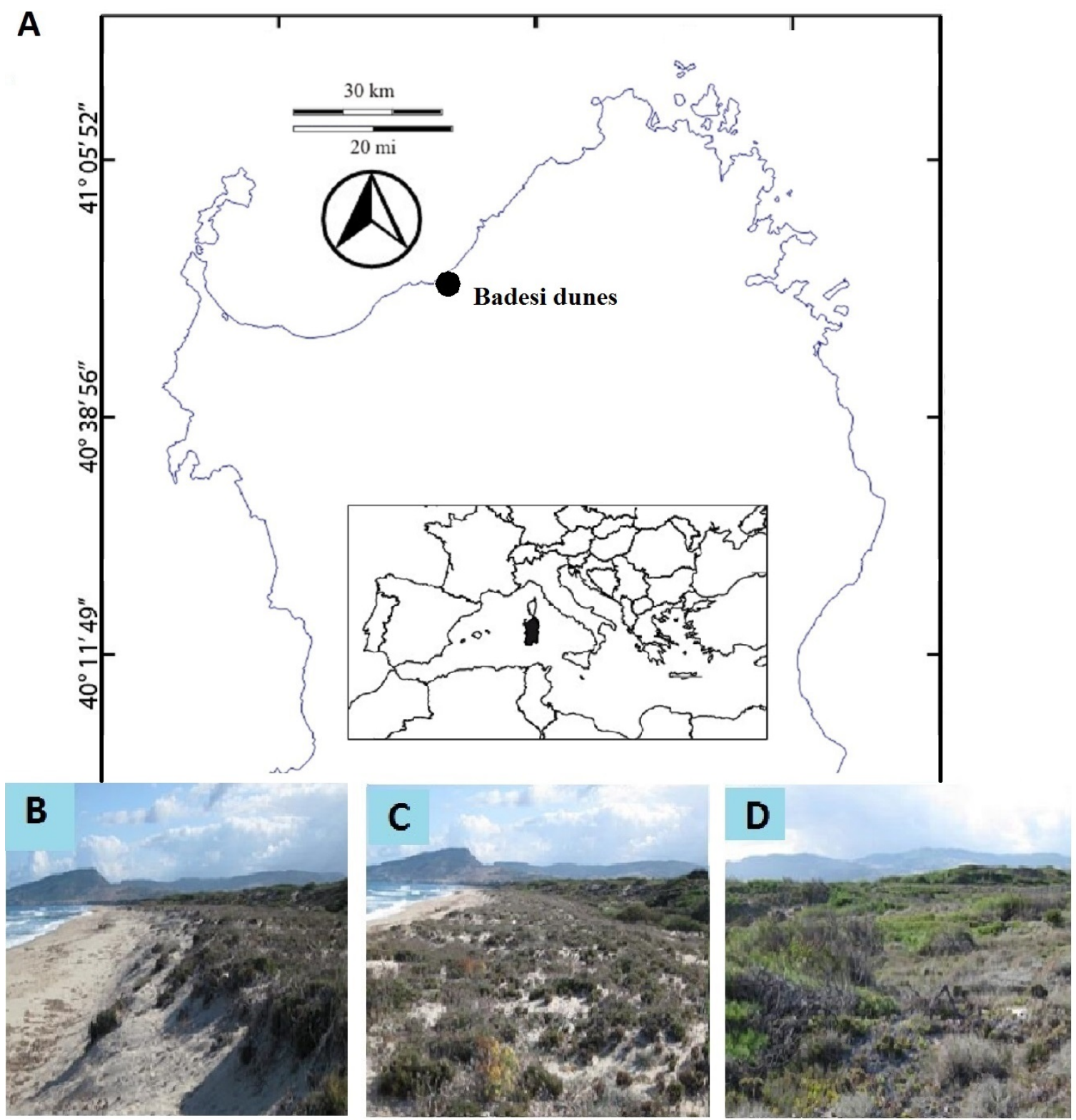

FIG. 1. (A) Map of the location of the study site, and photographs of the dune zones at Badesi

(Sardinia, Italy). (B) Fore-dune, (C) middle-dune and (D) back-dune. 
Figure 2

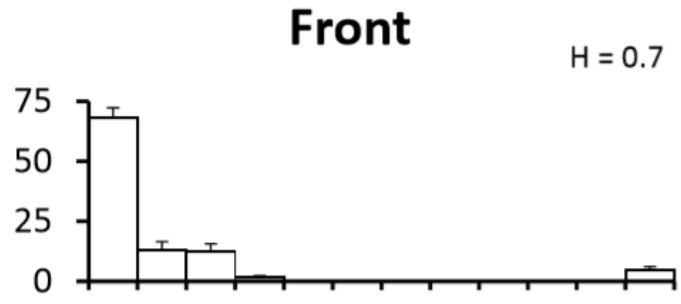

Fore top
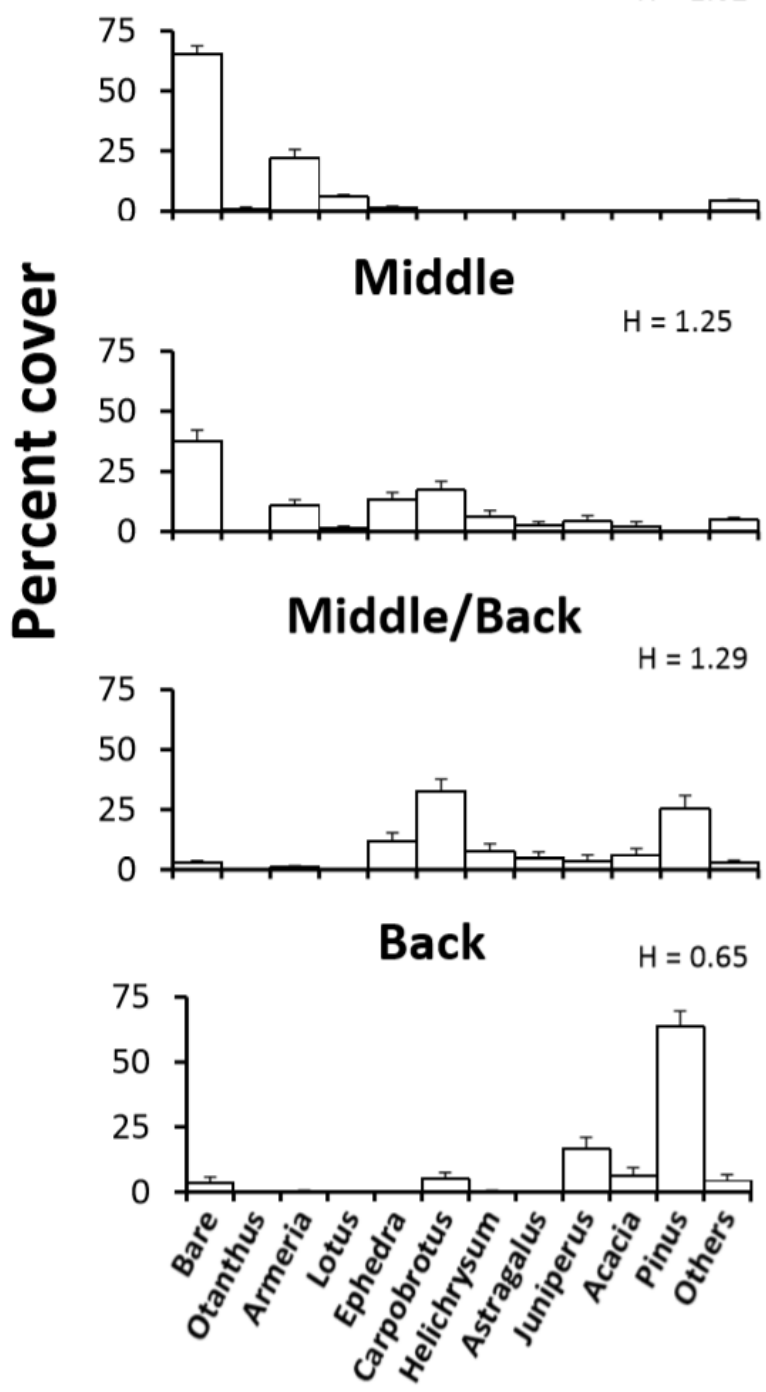
FIG. 2. Plant zonation (mean percent cover $+\mathrm{SE}$ ) at the Badesi dune. Transects parallel to the shoreline were sampled at $2 \mathrm{~m}$ intervals with $0.5 * 0.5 \mathrm{~m}$ quadrats (60/zone) to estimate percent cover. $\mathrm{H}$ is the Shannon diversity index. 
Figure 3

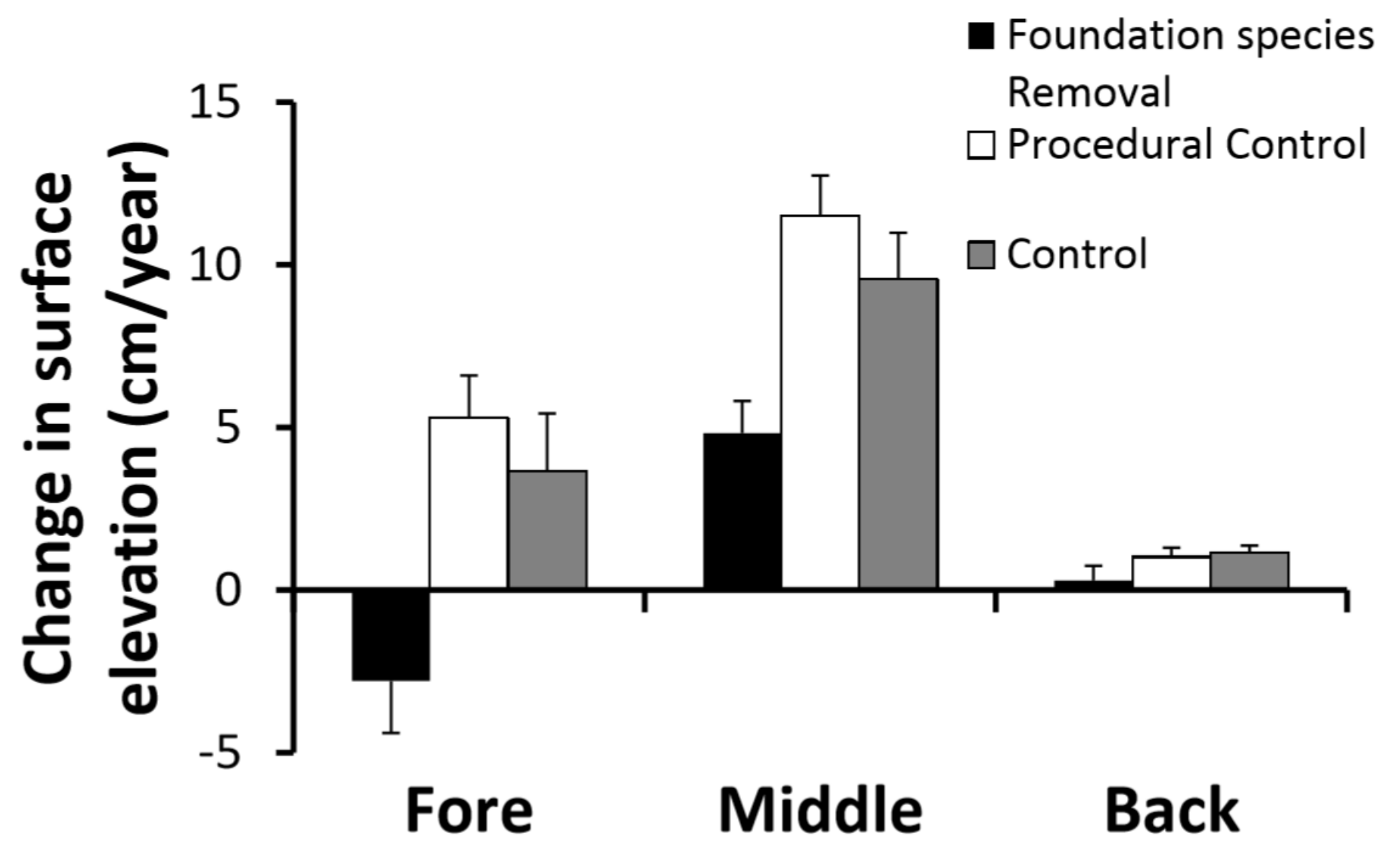

FIG. 3. Surface elevation or sand erosion/deposition balance (mean + SE) of the foundation plant species removal experiment in the three dune zones, measured for three years. 
Figure 4
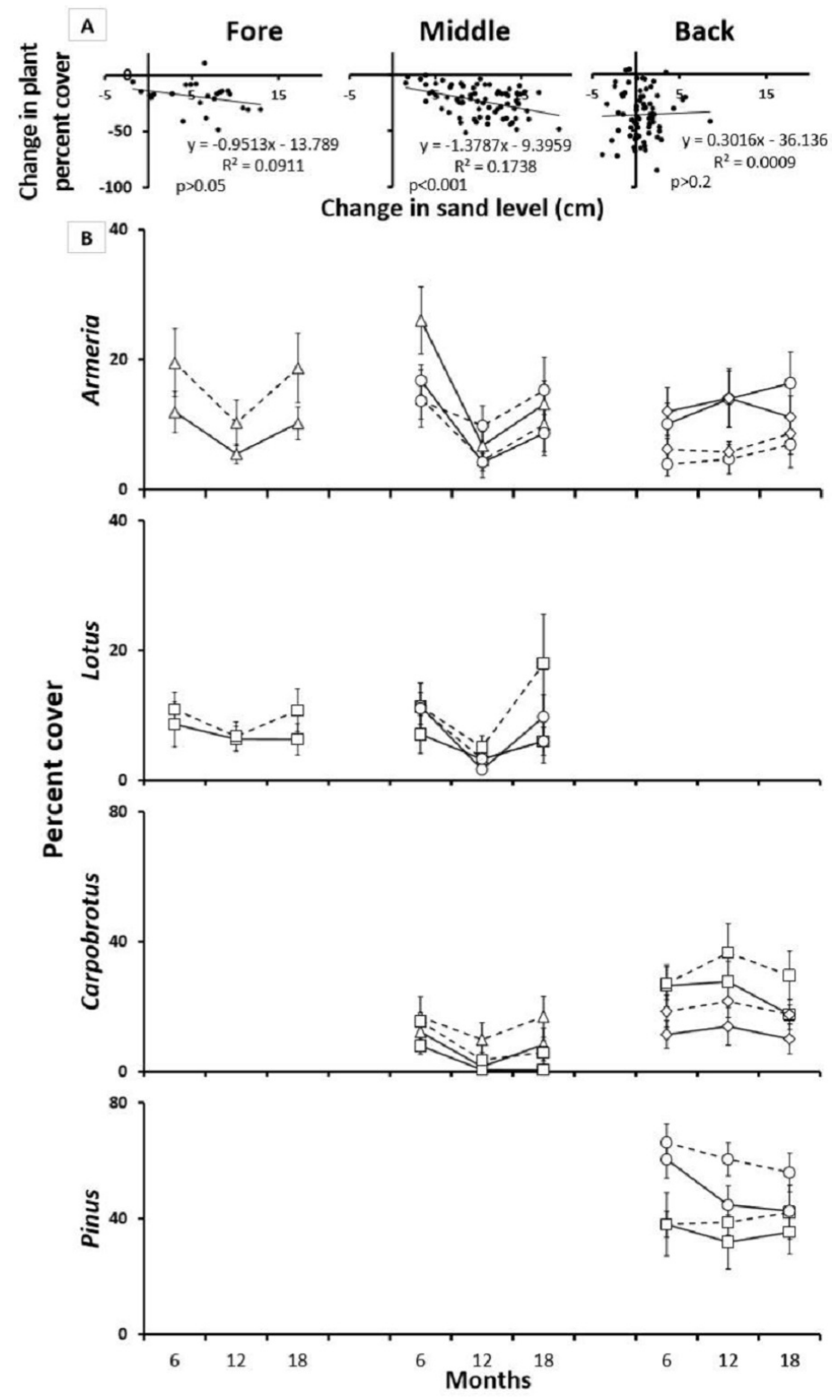

FIG. 4. (A) Relationship between sand burial and percent plant cover in the pair-wise reciprocal species removal experiments after 12 months in the fore, middle and back dune. (B) Reciprocal species removal: Armeria pungens $(\square)$, Lotus cytisoides $(\Delta)$, Carpobrotus acinaciformis $(\bigcirc)$,

Pinus spp. $(\diamond)$, Species control (—), Reciprocal species removal (- - ). Results of pair-wise reciprocal species removal experiments after 18 months in the fore, middle and back-dune. 
Figure 5


FIG. 5. Seeds distribution (mean $+\mathrm{SE}$ ) of common dune plants across zones under adult plants and in adjacent unvegetated sand. Data are given separately for conspecific and non-conspecific seeds. 
Figure 6
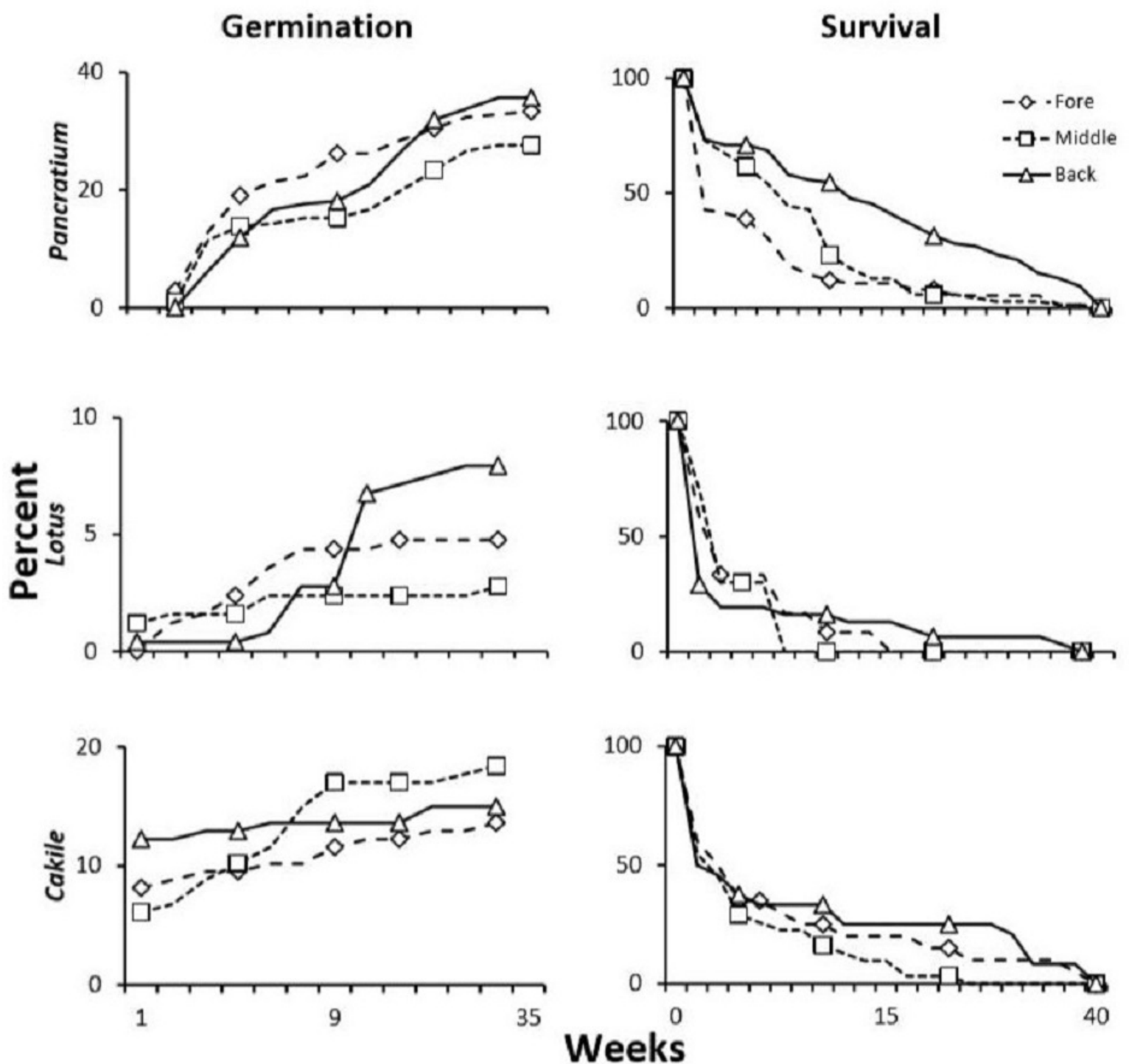

FIG. 6. Results of the seed transplant experiment where germination permeable net bags of locally collected seeds $(n=21 /$ zone/species $)$ from dehiscing seed heads were transplanted to the fore, middle and back-dune with and without plant neighbors and scored for germination and seedling survivorship. Data are percent survivorship and germination of the total potential. 
Figure 7
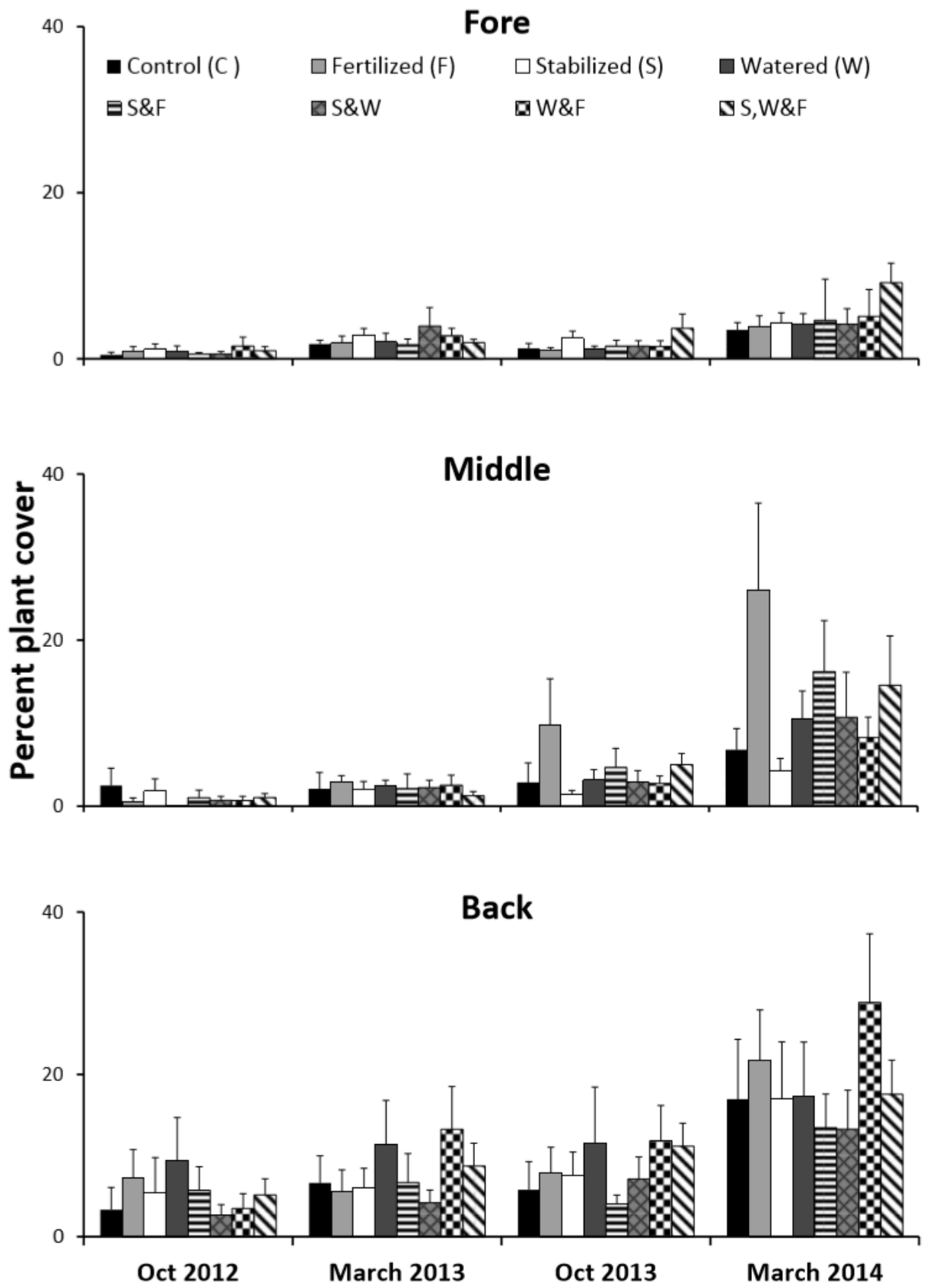

FIG. 7. Physical stress alleviation experiment. Percent plant cover (mean + SE) of the fully factorial manipulation of water availability, nutrient availability and substrate stability during 2 
years in the fore-, middle- and back-dune. No single or combination of stress alleviation treatments affected plant cover, but higher recovery occurred in back zone. 
Figure 8
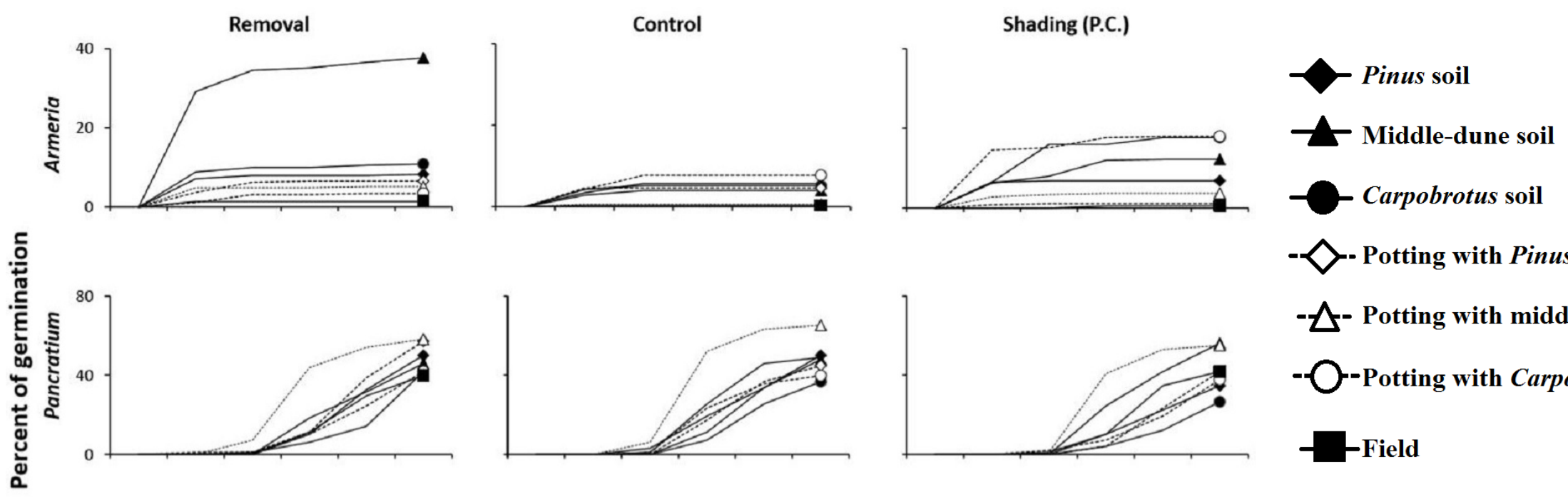

- Potting with Pinus needles

$-\triangle-$ Potting with middle-dune soil

-O-Potting with Carpobrotus soil


FIG. 8. Back dune competitive release experiment. Germination of Armeria, Pancratium and Lotus seeds sowed in different soils and in Treatment field (no canopy), Control (under canopy) and Procedural controls (Pinus removal with shade cloth to simulate canopy shading, P.C.). $\mathrm{N}=8$ /treatment. Data are percent of seeds germinated out of the total potential. 
Figure 9



FIG. 9. Conceptual model of the assemble rules of the Badesi sand dune plant community. 
Appendix

TABLE S1. Seeds distribution experiment. Results of three-way ANOVAs considering the species, the substrate (under adult vs bare sand) and the seeds category (conspecific vs other seeds) all as orthogonal and fix factors (Fig. 5).

\begin{tabular}{lcccccccccccc} 
& \multicolumn{3}{l}{ Front } & \multicolumn{3}{c}{ Fore Top } & \multicolumn{3}{c}{ Middle } & \multicolumn{3}{c}{ Back } \\
Source & df & F & $\mathrm{p}$ & $\mathrm{df}$ & $\mathrm{F}$ & $\mathrm{p}$ & $\mathrm{df}$ & $\mathrm{F}$ & $\mathrm{p}$ & $\mathrm{df}$ & $\mathrm{F}$ & $\mathrm{p}$ \\
\hline Species (sp) & 1 & 0.00 & 0.9965 & 2 & 0.70 & 0.4998 & 1 & 0.35 & 0.5572 & 1 & 0.76 & 0.3861 \\
Substrate (su) & 1 & 6.67 & 0.0118 & 1 & 8.89 & 0.0036 & 1 & 13.27 & 0.0005 & 1 & 8.49 & 0.0048 \\
Seeds & 1 & 8.36 & 0.0051 & 1 & 0.60 & 0.4395 & 1 & 0.20 & 0.6550 & 1 & 0.61 & 0.4389 \\
category (se) & 1 & & & & & & & & & & & \\
spXsu & 1 & 0.10 & 0.7515 & 2 & 0.53 & 0.5905 & 1 & 0.35 & 0.5546 & 1 & 0.75 & 0.3907 \\
spXse & 1 & 0.00 & 0.9439 & 2 & 4.23 & 0.0170 & 1 & 15.74 & 0.0002 & 1 & 10.04 & 0.0022 \\
suXse & 1 & 6.56 & 0.0125 & 1 & 0.22 & 0.6432 & 1 & 0.25 & 0.6188 & 1 & 0.70 & 0.4048 \\
spXsuXse & 1 & 0.11 & 0.7415 & 2 & 3.45 & 0.0354 & 1 & 12.59 & 0.0007 & 1 & 8.34 & 0.0051 \\
RES & 72 & & & 108 & & & 72 & & & 72 & & \\
\hline
\end{tabular}

831 
TABLE S2. Survivorship of natural seedlings marked in October 2013 that survived after 3 seasons in each zone. For each zone and species, the seedlings were marked associated with conspecific adults and in bare substrate $>30 \mathrm{~cm}$ from adult vegetation.

Carpobrotus seedlings were only found under adult Carpobrotus, so all 50 marked Carpobrotus seedlings were with conspecifics.

\begin{tabular}{|c|c|c|c|c|c|c|c|c|c|}
\hline \multirow[b]{2}{*}{ Zone } & \multirow[b]{2}{*}{ Distance } & \multicolumn{2}{|c|}{ Lotus } & \multicolumn{2}{|c|}{ Pancratium } & \multicolumn{2}{|c|}{ Armeria } & \multicolumn{2}{|c|}{ Carpobrotus } \\
\hline & & $\begin{array}{l}\mathrm{N}^{\circ} \text { of } \\
\text { marked } \\
\text { seedlings }\end{array}$ & $\begin{array}{c}\text { Survivorship } \\
(\%)\end{array}$ & $\begin{array}{l}\mathrm{N}^{\circ} \text { of } \\
\text { marked } \\
\text { seedlings }\end{array}$ & $\begin{array}{c}\text { Survivorship } \\
(\%)\end{array}$ & $\begin{array}{l}\mathrm{N}^{\circ} \text { of } \\
\text { marked } \\
\text { seedlings }\end{array}$ & $\begin{array}{c}\text { Survivorship } \\
(\%)\end{array}$ & $\begin{array}{l}\mathrm{N}^{\circ} \text { of } \\
\text { marked } \\
\text { seedlings }\end{array}$ & $\begin{array}{l}\text { Survivorship } \\
(\%)\end{array}$ \\
\hline \multirow{2}{*}{ Fore } & $\begin{array}{l}\text { Adjacent } \\
\text { bare sand }\end{array}$ & 25 & 0 & 25 & 0 & & & & \\
\hline & $\begin{array}{c}\text { Next to } \\
\text { adult }\end{array}$ & 25 & 0 & 25 & 4 & & & & \\
\hline \multirow{2}{*}{ Middle } & $\begin{array}{c}\text { Adjacent } \\
\text { bare sand }\end{array}$ & 25 & 4 & 25 & 0 & 25 & 32 & & \\
\hline & $\begin{array}{c}\text { Next to } \\
\text { adult }\end{array}$ & 25 & 4 & 25 & 0 & 25 & 12 & & \\
\hline \multirow{2}{*}{ Back } & $\begin{array}{l}\text { Adjacent } \\
\text { bare sand }\end{array}$ & & & & & 25 & 84 & & \\
\hline & $\begin{array}{l}\text { Next to } \\
\text { adult }\end{array}$ & & & & & 25 & 80 & 50 & 80 \\
\hline
\end{tabular}


832 TABLE S3. Physical stress alleviation experiment. Two-way ANOVA results with zone and treatment as orthogonal and fix factors 833 (Fig. 7).

834

\begin{tabular}{lccc}
\multicolumn{1}{c}{ Source } & df & F & p \\
\hline Zone (zo) & 2 & 18.30 & 0.0000 \\
Treatment (tr) & 9 & 1.70 & 0.0917 \\
zoXtr & 18 & 0.87 & 0.6151 \\
RES & 210 & & \\
\hline
\end{tabular}


Figure S1

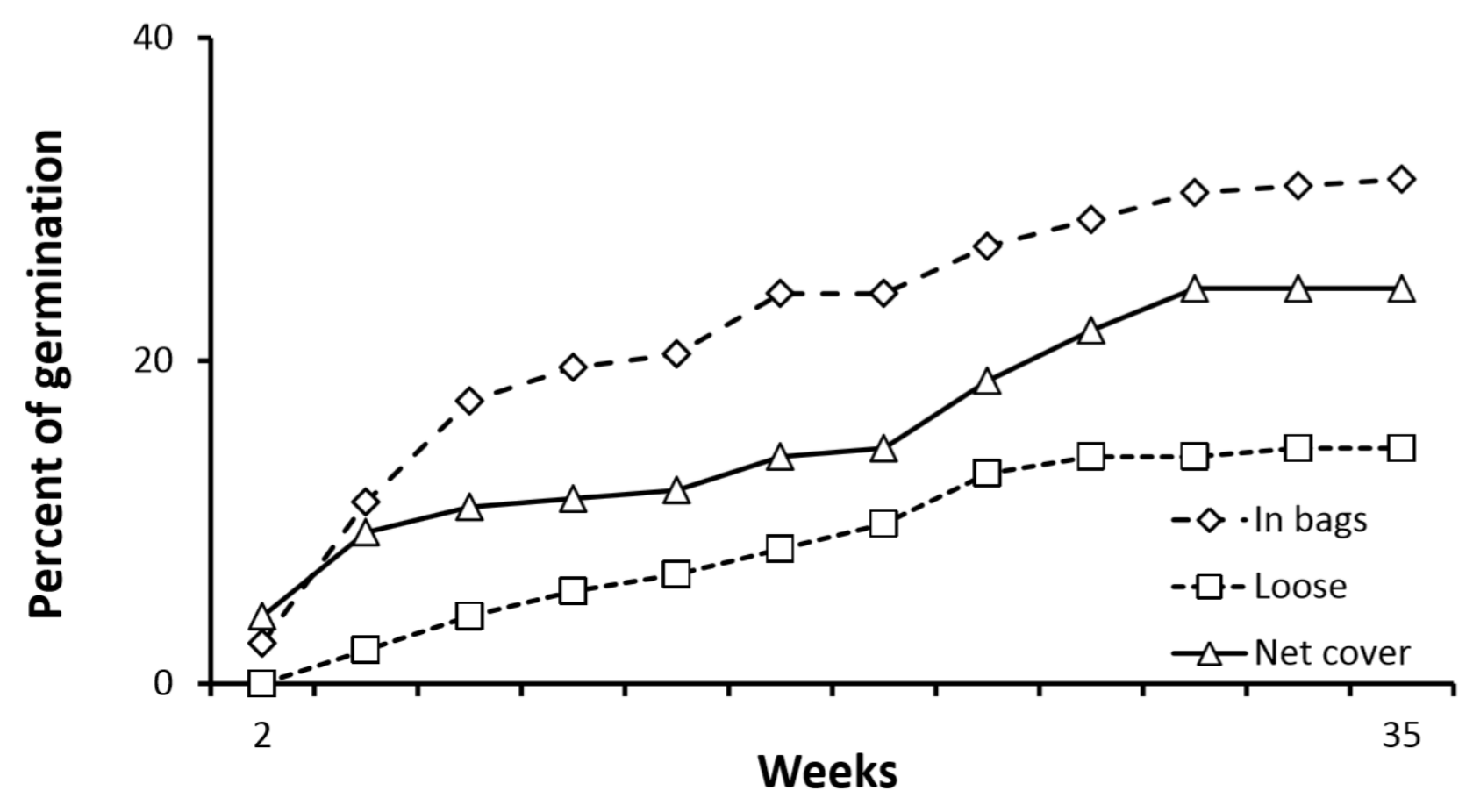

FIG. S1. Seeds erosion experiment. Germination in the fore-dune where Pancratium seeds were transplanted in germination permeable net bags, loose in the soil and loose in the soil but covered at the surface with nylon mesh to limit erosion $(\mathrm{n}=8$ treatment). Data are percent germination of the total potential. 